\title{
Cyclic test data of six unreinforced masonry walls with different boundary conditions
}

\author{
Sarah Petry, and Katrin Beyer, ${ }^{\text {a) }}$ M.EERI
}

Previous test data on unreinforced masonry walls focused on the global response of the wall. A new dataset on six wall tests, which is publically available, allows linking global to local deformations of masonry walls, which can be useful for advancing performance-based design and assessment methods for unreinforced masonry buildings. This data paper presents the results of a test series on six identical unreinforced masonry walls that were constructed using hollow clay brick units and standard cement-based mortar. The test units were subjected to quasi-static cycles of increasing drift demands and the tests differed with regard to the applied axial load and the moment restraint applied at the top of the walls. The walls were tested up to failure. Throughout the loading the deformations of the walls were recorded using a digital photogrammetric measurement system tracking the movement of 312 points per test unit.

\section{INTRODUCTION}

Performance-based design and assessment methods for unreinforced masonry structures require as input estimates of the drift capacity of masonry walls. Today's codes include only empirical drift capacity models for unreinforced masonry walls (e.g. CEN 2004) which result in significant dispersion of predicted to observed drift capacities (Frumento et al. 2009; Petry and Beyer 2014). To promote the use of performance-based design, better drift capacity models are required, which link explicitly the drift capacity of masonry walls based on assumed mechanisms and local deformation limits. Such models exist since several decades for reinforced concrete and steel structures (e.g. plastic hinge models with material strain limits, Priestley et al. 2007). To develop such models, test

\footnotetext{
a) Earthquake Engineering and Structural Dynamics Laboratory (EESD), School of Architecture, Civil and Environmental Engineering (ENAC), École Polytechnique Fédérale de Lausanne (EPFL), 1015 Lausanne, Switzerland.
} 
data for local and global deformation quantities are required. This paper presents such data for six unreinforced masonry wall tests.

\section{TEST OBJECTIVES}

When compared to previous tests on masonry walls (e.g. Ganz and Thürlimann 1984, Vermeltfoort et al. 1993, Bosiljkov et al. 2003, Magenes et al. 2008, Salmanpour et al. 2013, Gams and Tomaževič 2013), the tests series presented here is unique with respect to the following two aspects. First, all previous tests investigated only walls tested under a centric constant axial load with double-fixed or cantilever boundary conditions (which correspond to shear spans $H_{0}$ equal to 0.5 and 1.0 times the wall height $H$ ), while this series investigates a larger range of shear spans $\left(H_{0}=0.5,0.75\right.$ and $\left.1.5 H\right)$ and three axial load ratios. To the knowledge of the authors, the only wall that had been subjected to boundary conditions different to double-fixed or cantilever was test unit W4 by Ganz and Thürlimann (1984), who studied the wall behavior under a constant axial load at a constant eccentricity and monotonically increasing horizontal displacement. Second, the tests are unique with regard to the local deformations recorded. A grid of four LEDs per full brick whose positions were recorded continuously by a digital photogrammetric measurement system allows computing the average strain sensor for each brick and crack width of all joints during loading. Salmanpour et al. (2013) and Gams and Tomaževič (2013) used digital image correlation (DIC) for measuring local deformations of URM walls. The advantage of the LED-based system relates to the much smaller file size for one measurement frame allowing hence a larger measurement frequency.

\section{ORGANISATION OF THE PAPER}

The paper outlines the test program, the geometry and material test data of the six masonry walls, the instrumentation and the loading protocol. It describes the observed behavior and the recorded data. Two sets of data are provided: The first set or unprocessed data corresponds to the rawdata of the conventional and optical measurement data, which were recorded at different frequencies. In the second set of data (processed data), the optical measurement data was smoothed to remove inherent noise, the coordinate system was rotated to align the measurement axes with the axes of the test unit and the data synchronized with the data of the conventional instruments. The second set of conventional data has been carefully processed to remove any bias or data that is not linked to the actual behavior of the test data (e.g. offsets because conventional instruments were moved during testing). It also includes a number of additional channels computed from recorded channels such as the total applied axial force, the top and bottom 
moment of the walls and the average drift. This data is provided to allow potential users of the data to quickly evaluate the global response of the walls.

\section{TEST PROGRAM AND TEST SETUP}

The experimental campaign comprised six tests on masonry walls that all had the same dimensions $(H=2.25 \mathrm{~m}, L=2.01 \mathrm{~m}, T=0.20 \mathrm{~m})$. The walls were named PUP1-6 and represented the first story of an unreinforced masonry wall in a four-story building with reinforced concrete slabs (Petry and Beyer 2014). The moment, axial force and shear force at the top of the walls were introduced by three actuators (Figure 1). All actuators had a force capacity of $\pm 1000 \mathrm{kN}$ and a displacement capacity of $\pm 500 \mathrm{~mm}$. The distance between the axes of the two vertical cylinders was $L_{a c t}=2.4 \mathrm{~m}$ and the distance of the horizontal cylinder to the upper edge of the wall $H_{a c t}=0.275 \mathrm{~m}$. The vertical actuators were controlled in such a way that the axial force applied to the wall during testing remained constant (Walter and Bai 2011). In addition, for PUP1 the vertical actuators maintained a zero rotation of the loading beam representing therefore double-fixed boundary conditions. For PUP2-5 the control of the vertical actuators was coupled to the force of the horizontal actuator in such a manner that the shear span $H_{0}$ remained constant throughout the test. In external walls of URM buildings the axial load $N$ and the shear span $H_{0}$ depend on the loading direction, e.g. Petry and Beyer (2014). When the structure is loaded towards the considered external wall, $N$ and $H_{0}$ increase and when loading of the structure is reversed, $N$ and $H_{0}$ decrease. If these loading directions are regarded separately, PUP4 and PUP5 represent an external wall, once on the compression side and once on the tension side of the structure. In order to investigate the influence of varying axial force $N$ and shear span $H_{0}$ of external walls on their force-displacement response, we defined $N$ and $H_{0}$ of PUP6 as linear functions of the applied horizontal force $F_{1}$ using following formula:

$$
\begin{gathered}
N=\frac{N_{\text {max }}+N_{\text {min }}}{2}-F_{1} \cdot \frac{N_{\text {max }}-N_{\text {min }}}{F_{1, \text { max }}-F_{1, \text { min }}} \\
H_{0}=\frac{H_{0, \text { max }}+H_{0, \text { min }}}{2}-F_{1} \cdot \frac{H_{0, \text { max }}-H_{0, \text { min }}}{F_{1, \text { max }}-F_{1, \text { min }}}
\end{gathered}
$$

where $N_{\max }=-619 \mathrm{kN}, N_{\min }=-219 \mathrm{kN}, H_{0, \text { min }}=0.75 H$ and $H_{0, \max }=1.5 \mathrm{H}$ correspond to the boundary conditions of PUP4 and PUP5, while $F_{1, \max }=-F_{1, \min }=133 \mathrm{kN}$ was determined as the average of the lateral force capacities obtained from PUP4 and PUP5. 
Table 1 summarizes the applied axial load, the shear span and the equations for the control of the vertical actuators.

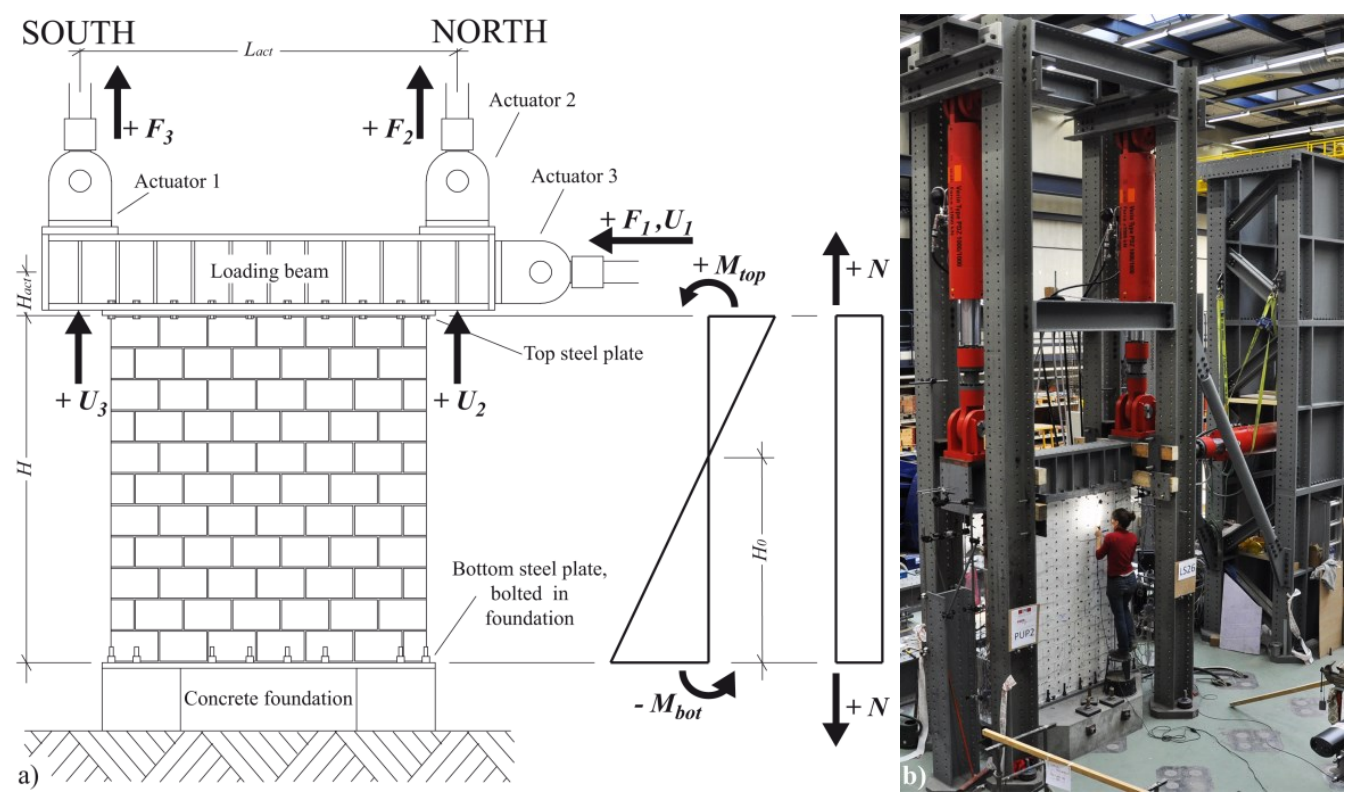

Figure 1. (a) Test setup with sign conventions after processing and (b) photo showing the test setup with the three actuators

Table 1. Test program

\begin{tabular}{|c|c|c|c|c|}
\hline Specimen & $\begin{array}{l}\text { Axial } \\
\text { force } N\end{array}$ & $\begin{array}{l}\text { Axial stress } \\
\text { ratio } \sigma_{0} / f_{u}\end{array}$ & $\begin{array}{l}\text { Shear } \\
\text { span } H_{0}\end{array}$ & Equations for control of vertical actuators \\
\hline PUP1 & $-419 \mathrm{kN}$ & 0.18 & $0.5 H$ & $\begin{array}{ll}\text { Actuator 2: } & F_{2}=N-F_{3} \\
\text { Actuator 3: } & U_{3}=U_{2}\end{array}$ \\
\hline PUP2 & $-419 \mathrm{kN}$ & 0.18 & $0.75 H$ & Actuator $2 \& 3$ : \\
\hline PUP3 & $-419 \mathrm{kN}$ & 0.18 & $1.5 H$ & Actuator $\angle \& 5$ \\
\hline PUP4 & $-619 \mathrm{kN}$ & 0.26 & $1.5 H$ & $F_{2,3}=\frac{N}{\Omega} \pm c \cdot F_{1}$ \\
\hline PUP5 & $-219 \mathrm{kN}$ & 0.09 & $0.75 H$ & \\
\hline PUP6 & $\begin{array}{l}-619 \mathrm{kN} \\
-219 \mathrm{kN}\end{array}$ & $\begin{array}{l}0.26 \\
0.09\end{array}$ & $\begin{array}{r}1.5 H \\
0.75 H\end{array}$ & $\begin{array}{l}\text { Actuator 2 \& 3: } \\
\qquad F_{2,3}=\frac{N}{2}+c_{1} \cdot F_{1} \pm c_{2} \cdot F_{1}^{2}\end{array}$ \\
\hline$H$ & \multicolumn{4}{|c|}{ Height of the wall } \\
\hline$H_{0}$ & \multicolumn{4}{|c|}{$\begin{array}{l}\text { Shear span } \\
\text { Total axial load applied to the wall }\end{array}$} \\
\hline$N$ & \multicolumn{4}{|c|}{ Total axial load applied to the wall } \\
\hline$F_{2,3}$ & \multicolumn{4}{|c|}{ Forces of the two vertical actuators } \\
\hline$F_{1}$ & \multicolumn{4}{|c|}{ Force of the horizontal actuator } \\
\hline$U_{2,3}$ & \multicolumn{4}{|c|}{ Vertical displacement of the two vertical actuators with respect to the ground } \\
\hline$c$ & \multicolumn{4}{|c|}{$\begin{array}{l}\text { Constant describing the dependency between } F_{2,3} \text { and } F_{I} \text { which determines the moment } \\
\text { profile. The value of this constant depends on } H_{0} \text { and the geometry of the test setup. }\end{array}$} \\
\hline$c_{1}$ and $c_{2}$ & \multicolumn{4}{|c|}{$\begin{array}{l}\text { Constants describing the dependency between } F_{2,3} \text { and } F_{l} \text { including the variation of the shear } \\
\text { span } H_{0} \text { and the axial load } N \text { for PUP6. }\end{array}$} \\
\hline
\end{tabular}

The masonry walls were constructed on steel plates that had been prepared by gluing a layer of quartz sand $(\mathrm{d}=1-3 \mathrm{~mm})$ onto the steel plate (Figure 2.a and 2.b). After waiting for at least 28 days (age at the day of testing: see Table 2) a layer of 5-10 mm cement mortar was added on top of the wall and another steel plate, which had been prepared in 
the same manner as the bottom steel plates, together with the loading beam were placed on top of the wall. The wall was prestressed vertically and then transported by crane to the test stand (Figure 2.c). In the test stand the bottom steel plate was bolted to a concrete foundation which remained fixed to the laboratory's strong floor. The prestress applied for transportation was removed after application of the axial stress (LS0 to LS1) and before the LS1 measurements were taken. Nevertheless, the applied prestress was only a small fraction of the stress applied during LS0 to LS1 and should have no influence on the LS0 measurements.

For the optical measurement, the walls were prepared as follows: (1) first a grid was drawn on the naked walls; (2) then small adhesive stickers were glued at each grid point in order to indicate the positions of the LEDs; (3) the walls were painted white in order to improve the visibility of cracks during testing and the adhesive sticker were removed immediately after painting as long as the paint remained wet, leaving thus a small area $(\varnothing$ $=1.9 \mathrm{~cm})$ of naked brick surface; (4) cleaned and sandblasted steel discs $(\varnothing=2.0 \mathrm{~cm})$ were glued directly onto the brick using a plasticine glue; (5) the plastic feet of the LEDs were fixed onto the steel discs using a hot-melt adhesive. After the test, the LEDs were removed from the plastic feet and reused. The aluminum supports of the linear variable differential transformer (LVDTs) at the short sides of the walls were fixed directly to the brick surface with a plasticine glue (the short sides of the walls remained unpainted for this reason, see Figure 2.c).
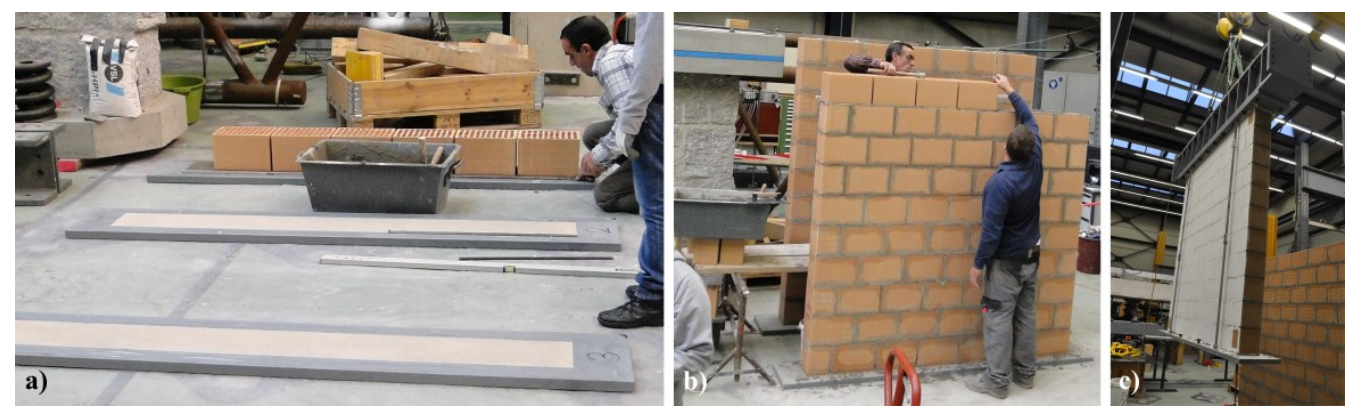

Figure 2. (a) Steel plates with layer of quartz sand, (b) test units during construction and (c) transportation of test unit to test stand

Table 2. Age at testing of the specimen for the compression tests (WUP), for the diagonal compression tests (QUP), for the shear tests (TUP) and for the six quasi-static cyclic tests on walls (PUP1-6)

\begin{tabular}{lrrrrrrrrrl}
\hline & WUP & QUP & TUP & PUP1 & PUP2 & PUP3 & PUP4 & PUP5 & PUP6 & \\
\hline Age at testing & 169 & 206 & 50 & 40 & 73 & 104 & 112 & 122 & 135 & days \\
\hline
\end{tabular}




\section{MATERIAL TEST DATA}

The masonry walls were constructed using Swiss hollow clay brick units and the standard cement mortar WEBER MUR MAXIT 920. The brick units had dimensions of $300 \times 190 \times 195 \mathrm{~mm}\left(L_{B} \times H_{B} \times W_{B}\right.$, Figure 3$)$. The geometric and mechanical properties of the units are summarized in Table 3 . Bed and head joints were fully mortared and had an average thickness of 10 to $12 \mathrm{~mm}$. Mortar samples were taken while constructing walls and wallettes for material tests. The mortar samples were tested when testing the corresponding walls and wallettes. The mortar properties for all types of specimen are summarized in Table 4.

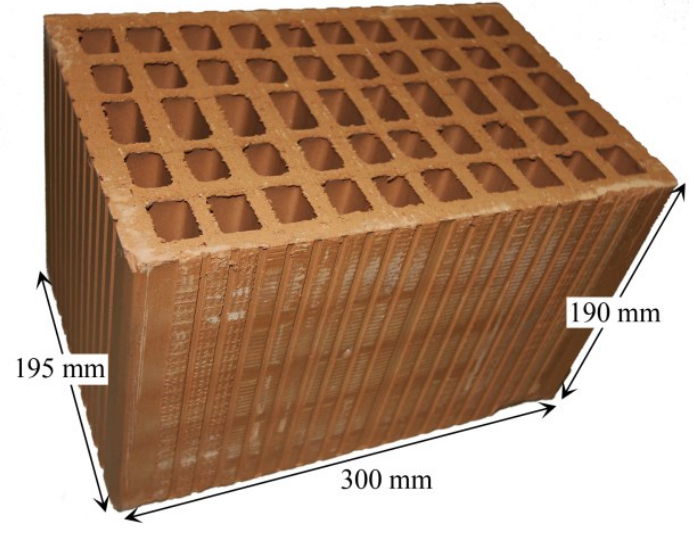

Figure 3. Investigated clay brick with average dimensions

Table 3. Derived brick and masonry properties

\begin{tabular}{llrl}
\hline Brick properties: & & & \\
\hline Compression tests, $\|$ to perforation & $f_{B, c, \|}$ & $35.0 \pm 7 \%$ & $\mathrm{MPa}$ \\
Compression, $\perp$ to perforation & $f_{B, c, \perp}$ & $9.4 \pm 8 \%$ & $\mathrm{MPa}$ \\
Flexural tensile, $\perp$ to perforation & $f_{B, f t}$ & $1.27 \pm 38 \%$ & $\mathrm{MPa}$ \\
\hline Masonry properties: & & & \\
\hline Compression strength & $f_{u}$ & $5.87 \pm 5 \%$ & $\mathrm{MPa}$ \\
E-modulus & $E$ & $3550 \pm 9 \%$ & $\mathrm{MPa}$ \\
Poisson ratio & $v$ & $0.20 \pm 19 \%$ & - \\
Peak shear strength & $\sigma_{\text {peak }}$ & $0.94 \sigma+0.27 \mathrm{MPa}$ & \\
Residual shear strength & $\sigma_{\text {res }}$ & $0.91 \sigma$ & \\
Diagonal tensile strength & $f_{t}$ & $0.50 \pm 10 \%$ & $\mathrm{MPa}$ \\
\hline
\end{tabular}


Table 4. Mortar properties corresponding to the mortar used for the construction of the specimen (WUP) for the compression tests, (QUP) for the diagonal compression tests, (TUP) for the shear tests and (PUP1-6) for the six quasi-static cyclic tests on walls

\begin{tabular}{llrrrrrrrrrl}
\hline $\begin{array}{l}\text { Mortar } \\
\text { properties: }\end{array}$ & WUP & QUP & TUP & PUP1 & PUP2 & PUP3 & PUP4 & PUP5 & PUP6 & \\
\hline $\begin{array}{l}\text { Compression } \\
\text { strength } f_{M, c}\end{array}$ & Mean & 10.5 & 14.5 & 13.3 & 8.99 & 9.75 & 12.0 & 11.7 & 9.87 & 9.02 & MPa \\
& dev. & 11 & 7 & 13 & 11 & 20 & 11 & 10 & 15 & 7 & $\%$ \\
Flexural tensile & Mean & 2.37 & 3.74 & 2.98 & 2.54 & 2.35 & 2.73 & 2.66 & 2.56 & 2.13 & MPa \\
strength $f_{M, f t}$ & Std. & 15 & 9 & 22 & 13 & 21 & 22 & 27 & 25 & 21 & $\%$ \\
\hline
\end{tabular}
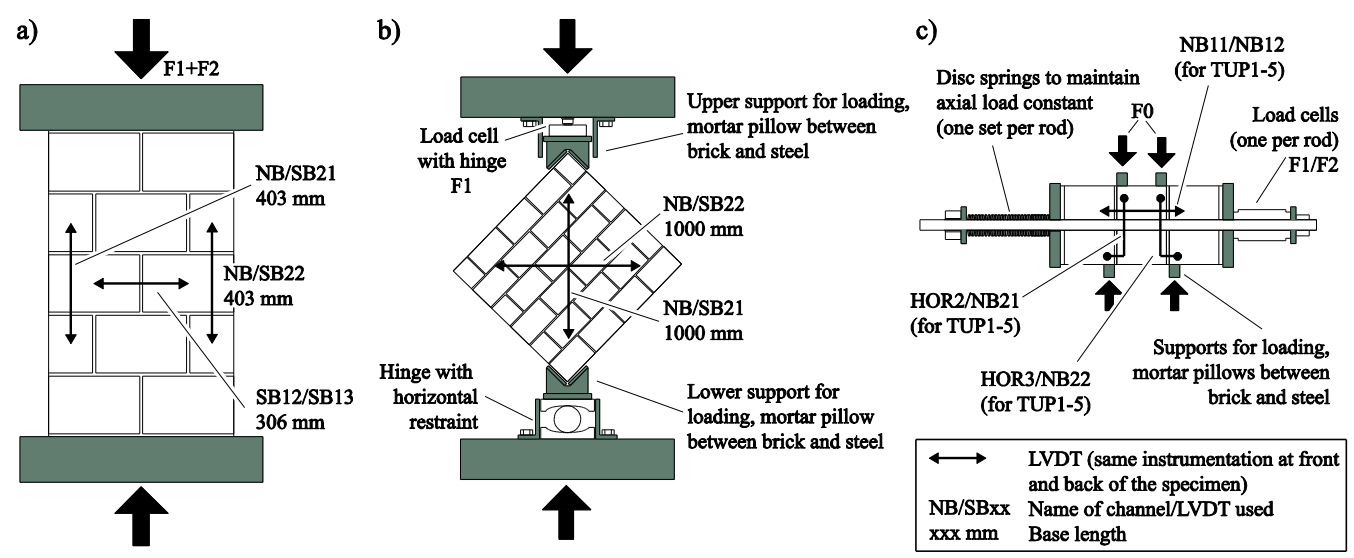

Figure 4. Test setups for the material tests

To determine the material properties of the masonry, three types of standard material tests were conducted (Figure 4): (1) the compression strength, elasticity modulus and Poisson's ratio were determined with compression tests (WUP1-5) on masonry wallettes (CEN 2002), (2) the peak shear strength and residual shear strength of the mortar brick interface were determined with shear tests (TUP1-10) on masonry triplets (CEN 2007) and (3) the diagonal tensile strength was determined with diagonal compression tests (QUP1-5) on square masonry wallettes (RILEM 1991). Figures 5 to 7 show for each material test a photo of a specimen and the test results. The mean masonry properties and coefficients of variation are summarized in Table 3. The data from material tests are provided together with the data of the wall tests. The organization of all data is described in Section "Test Data".

Note that the LVDTs indicated in Figure 4.c were only used for the first five triplet tests (TUP1-5), while for the test units TUP6-10 only the forces were recorded. Out of the ten triplet units, two units (TUP1 and TUP9) provided unreasonable results (the axial stress which we applied was too high and the bricks fractured before sliding in the joints 
could occur). These two units were omitted when computing residual and peak strength and are not shown in Figure 6.b.
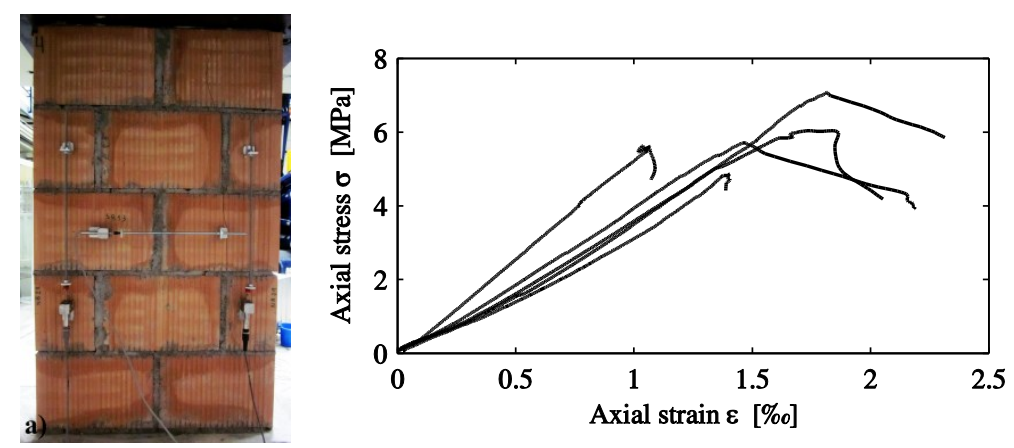

Figure 5. (a) Specimen for the compression tests with mounted measurement devices and (b) stress-strain relationships
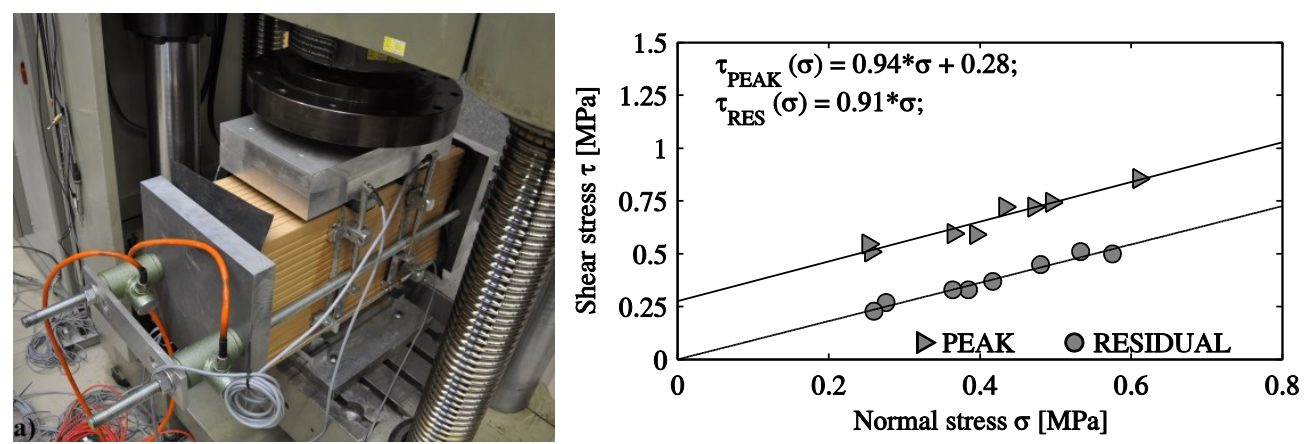

Figure 6. (a) Test setup for the shear tests with specimen and (b) applied normal stress versus resulting peak and residual shear strength of the mortar brick interface
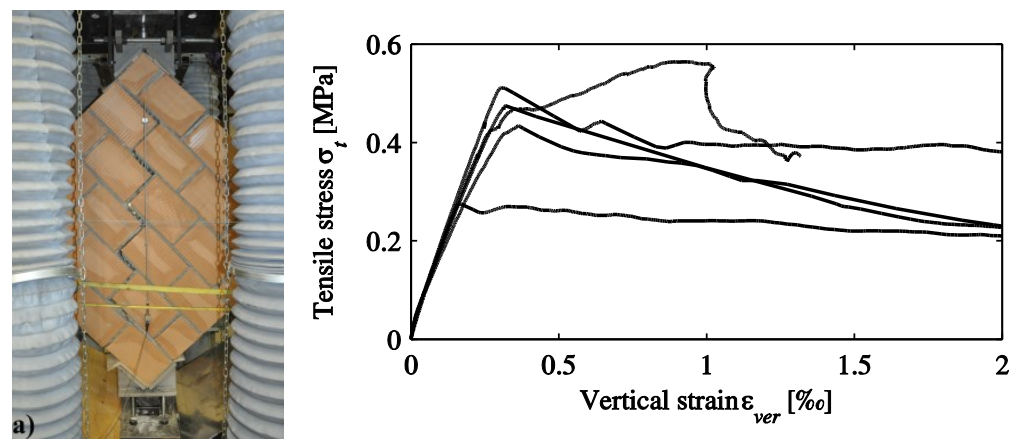

Figure 7. (a) Specimen for the diagonal compression tests with typical stair stepped crack along mortar joints and (b) stress-strain relationships

\section{INSTRUMENTATION}

The test units (PUP1-6) were instrumented with 42 conventional channels, which were recorded at a frequency of $1 \mathrm{~Hz}$. Next to global quantities (forces applied by actuators, displacements of top beam) some local deformations were measured with LVDTs and omega gauges. The locations of the conventional instruments and the base lengths (for instruments measuring local deformations) are indicated in Figure 8. The sign 
convention for the actuator forces and displacements of the top beam are also included in Figure 1. The exact position of the instruments U3, V3, U2 and V2 (Figure 8) varied between walls and the horizontal distance from the instrument to the outer edge of the wall is specified in Table 5 .

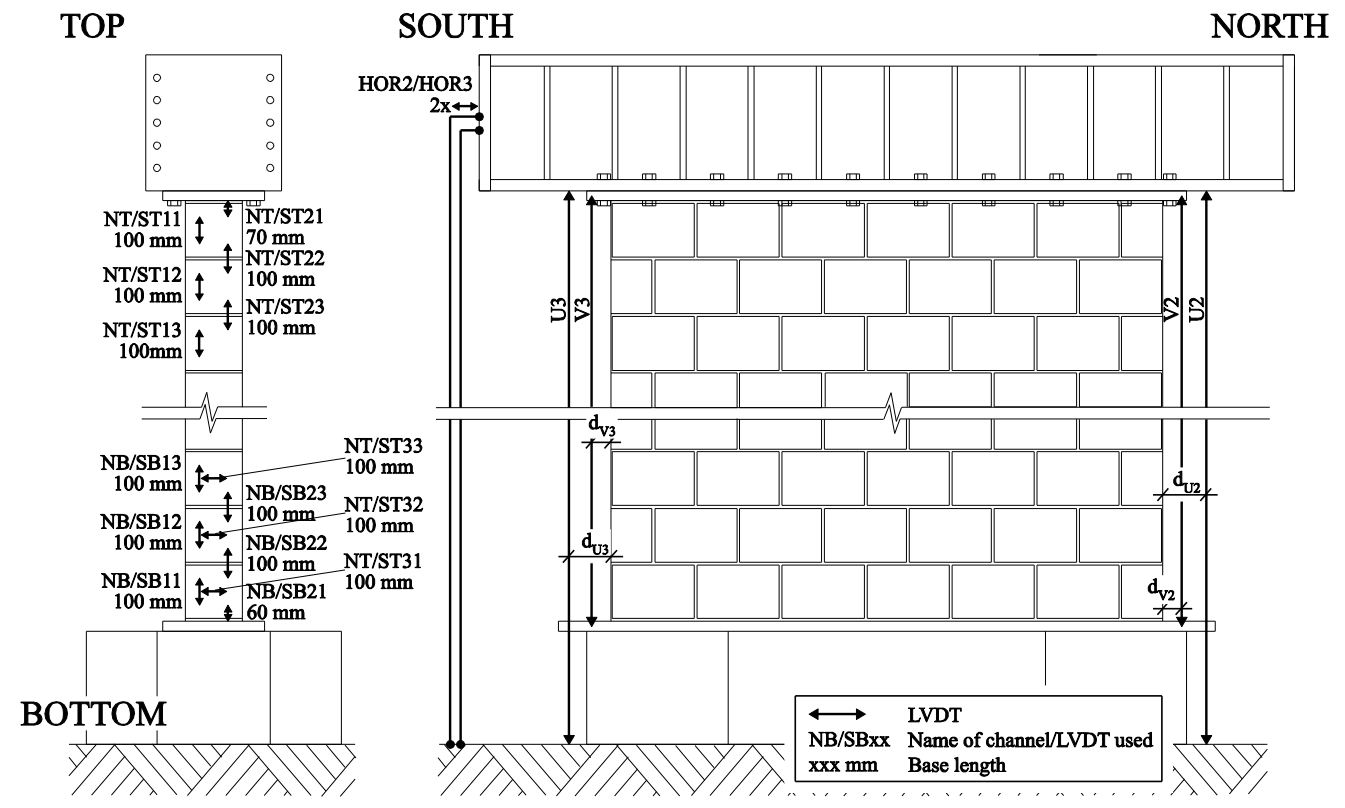

Figure 8. Location of the conventional measurement devices

Table 5. Distances defining the location of the conventional measurement devices U2, U3, V2 and V3 (Figure 8)

\begin{tabular}{|l|l|l|r|r|r|r|r|r|}
\hline Distance & $\begin{array}{l}\text { Channel } \\
\text { number }\end{array}$ & Unit & \multicolumn{1}{l|}{ PUP1 } & PUP2 & PUP3 & PUP4 & \multicolumn{1}{l|}{ PUP5 } & \multicolumn{1}{l|}{ PUP6 } \\
\hline $\mathrm{d}_{\mathrm{U} 2}$ & 5 & $\mathrm{~mm}$ & 75 & 205 & 218 & 150 & 145 & 147 \\
\hline $\mathrm{d}_{\mathrm{U} 3}$ & 7 & $\mathrm{~mm}$ & 75 & 230 & 218 & 155 & 140 & 140 \\
\hline $\mathrm{d}_{\mathrm{V} 2}$ & 9 & $\mathrm{~mm}$ & 45 & 150 & 150 & 230 & 250 & 254 \\
\hline $\mathrm{d}_{\mathrm{V} 3}$ & 10 & $\mathrm{~mm}$ & 45 & 150 & 150 & 234 & 257 & 270 \\
\hline
\end{tabular}

The optical measurements were performed with the commercially available system Optotrak from NDI (Optotrak Certus HD, NDI 2011). The photogrammetric system worked with two position sensors consisting each of three digital cameras (see Figure 9.a), which measured the 3D-coordinates of LEDs (see Figure 9.b) glued onto the test unit, foundation and loading beam (see Figure 10). During each measurement frame all LEDs illuminate one after each other and thus the positioning sensors recorded the $\mathrm{x}-\mathrm{y}$ and z-coordinates of each LED with a measurement frequency of $2 \mathrm{~Hz}$ (PUP1) or $4 \mathrm{~Hz}$ (PUP2-6). This system or a similar system that is based on the same principals has been used in several test campaigns, for example on reinforced concrete walls and columns 
(Lowes et al. 2012; Goodnight et al. 2013), but to our knowledge so far only on masonry spandrels Beyer et al. (2012a, b) and not on masonry walls.
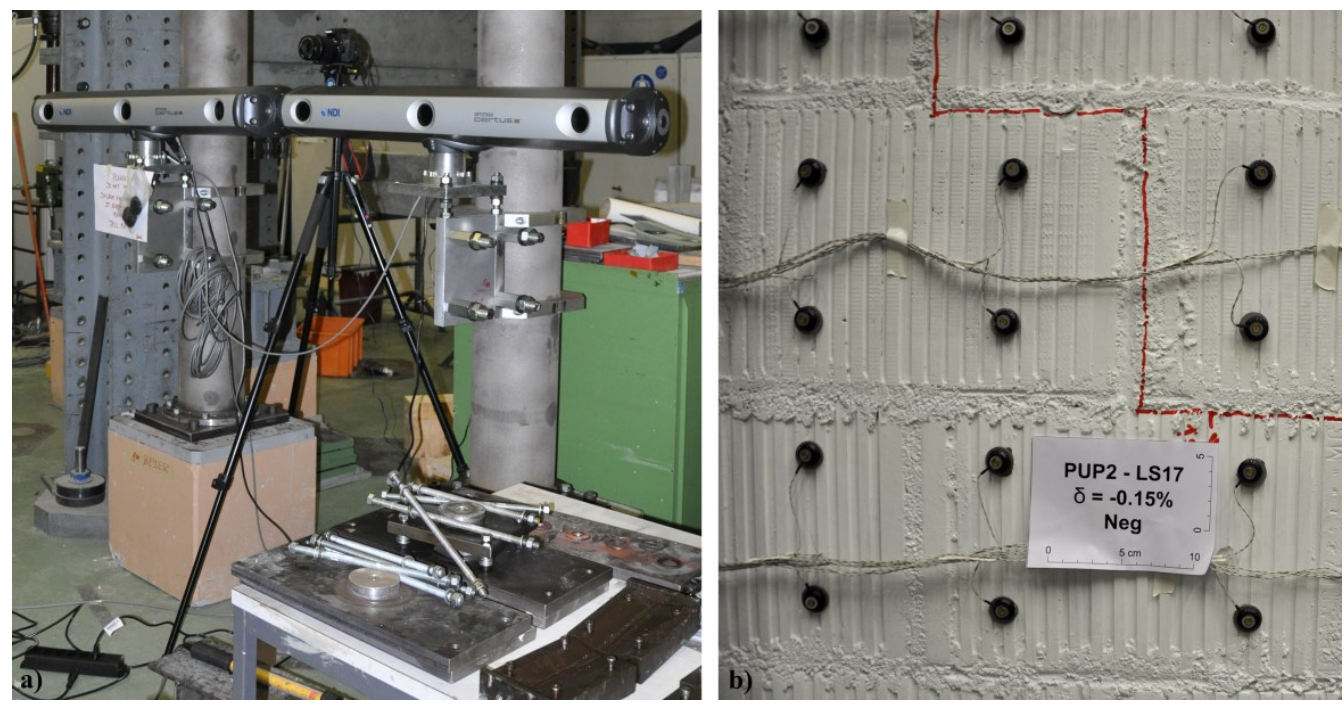

Figure 9. Measurement device used for the optical measurement system: (a) two position sensors consisting each of three cameras and (b) LEDs glued onto the masonry wall
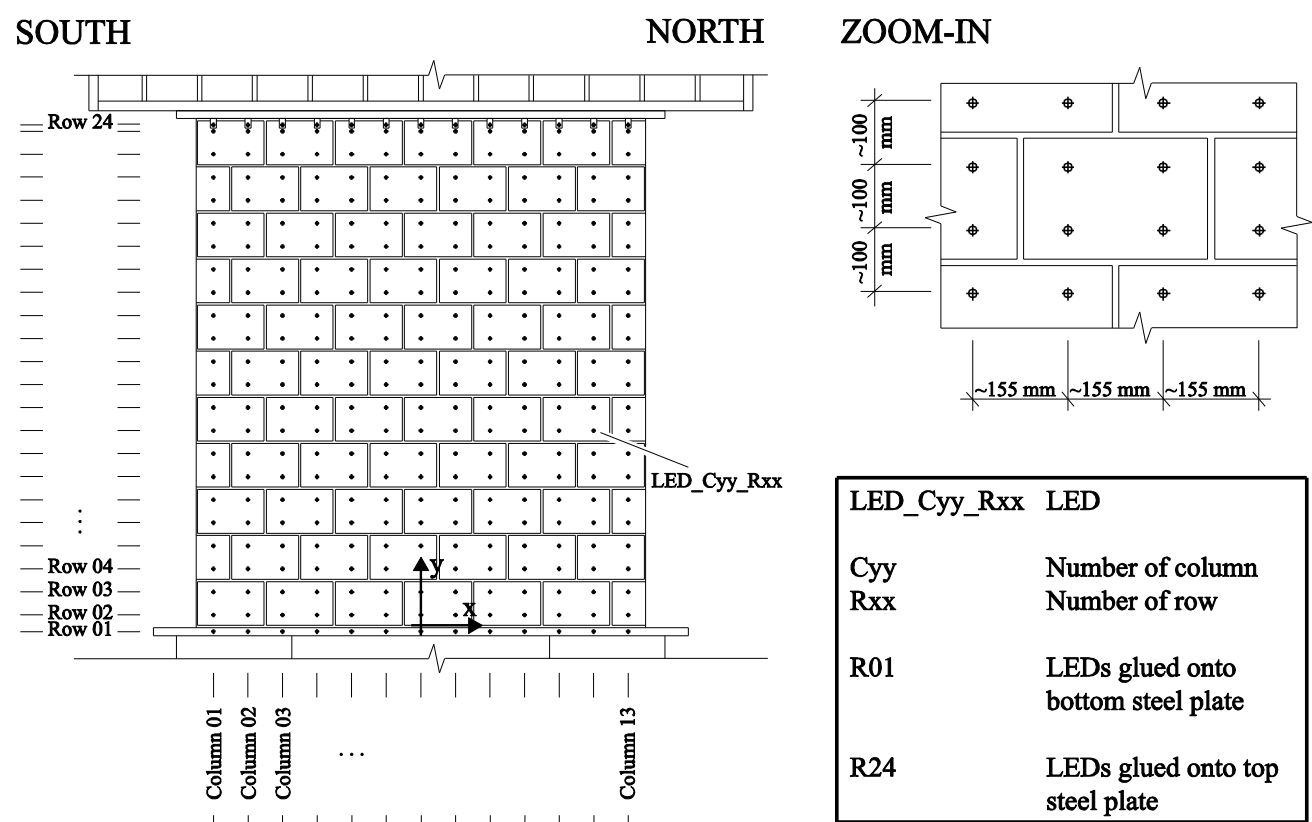

\begin{tabular}{|ll|}
\hline LED_Cyy_Rxx & LED \\
Cyy & $\begin{array}{l}\text { Number of column } \\
\text { Number of row }\end{array}$ \\
R01 & $\begin{array}{l}\text { LEDs glued onto } \\
\text { bottom steel plate }\end{array}$ \\
R24 & $\begin{array}{l}\text { LEDs glued onto top } \\
\text { steel plate }\end{array}$ \\
\hline
\end{tabular}

Figure 10. Positions of the LEDs for the optical measurement

Both systems used for the optical and conventional measurement worked independently from each other. In order to synchronize them we used the so-called "NDIchannel". This channel sent a voltage signal from the optical measurement system to the conventional measurement system when the optical measurement system was recording data. The synchronization itself was done after the test during the post-processing phase with the help of a self-written Matlab script. 


\section{TESTING PROCEDURE}

All tests were performed applying the following procedure (Figure 11): (0) Zero measurements were taken before any of the three actuators was connected to the test unit (load step LS0). (1) The vertical actuators were fixed to the loading beam at the top of the wall. (2) The axial force was applied by means of an identical force in both vertical actuators (LS1, $\left.F_{2,3}=N / 2\right)$. The resulting axial force acted therefore at the center line of the wall. (3) The horizontal actuator was connected to the loading beam. (4) The control functions for the vertical actuators were changed to the control functions indicated in Table 1. (5) The lateral loading history was started (LS2 - end). A load step of the drift controlled loading history corresponds to the peak of one half-cycle. At each load step, the loading was stopped, cracks were marked and photos were taken. During this period the conventional instruments were continuously recorded. The LEDs were only recorded for a period of approximately two minutes just before the test unit was unloaded (see Figure 11). The loading velocity was chosen in such a way that loading from one peak to the next took between 10 to $30 \mathrm{~min}$. All tests lasted for two to three days. Each evening all three actuators were unloaded in such a way that first the horizontal actuator was stopped between two loadsteps $\left(F_{1} \approx 0 \mathrm{kN}\right)$ and then the axial load was removed until $F_{2,3}$ $\approx 0 \mathrm{kN}$. During the night the actuators were switched off, but remained fixed to the test unit. The next day the axial load was reapplied $\left(F_{2}=F_{3}\right)$ and horizontal loading continued. Care was taken that the actuators were not switched off between peak load and horizontal load failure.

The amplitudes of the half-cycles corresponded to the following drift levels: $0.025 \%$, $0.05 \%, 0.1 \%, 0.15 \%, 0.2 \%, 0.3 \%, 0.4 \%, 0.6 \%, 0.8 \%$ and $1.0 \%$ (see Figure 11 ). Note that the cycles with amplitudes of $0.15 \%$ and $0.25 \%$ were not included in the loading history applied to PUP1, but added from PUP2 onwards since the performance of PUP1 deteriorated rapidly within the cycles with amplitudes of $0.2 \%$ and $0.3 \%$. 


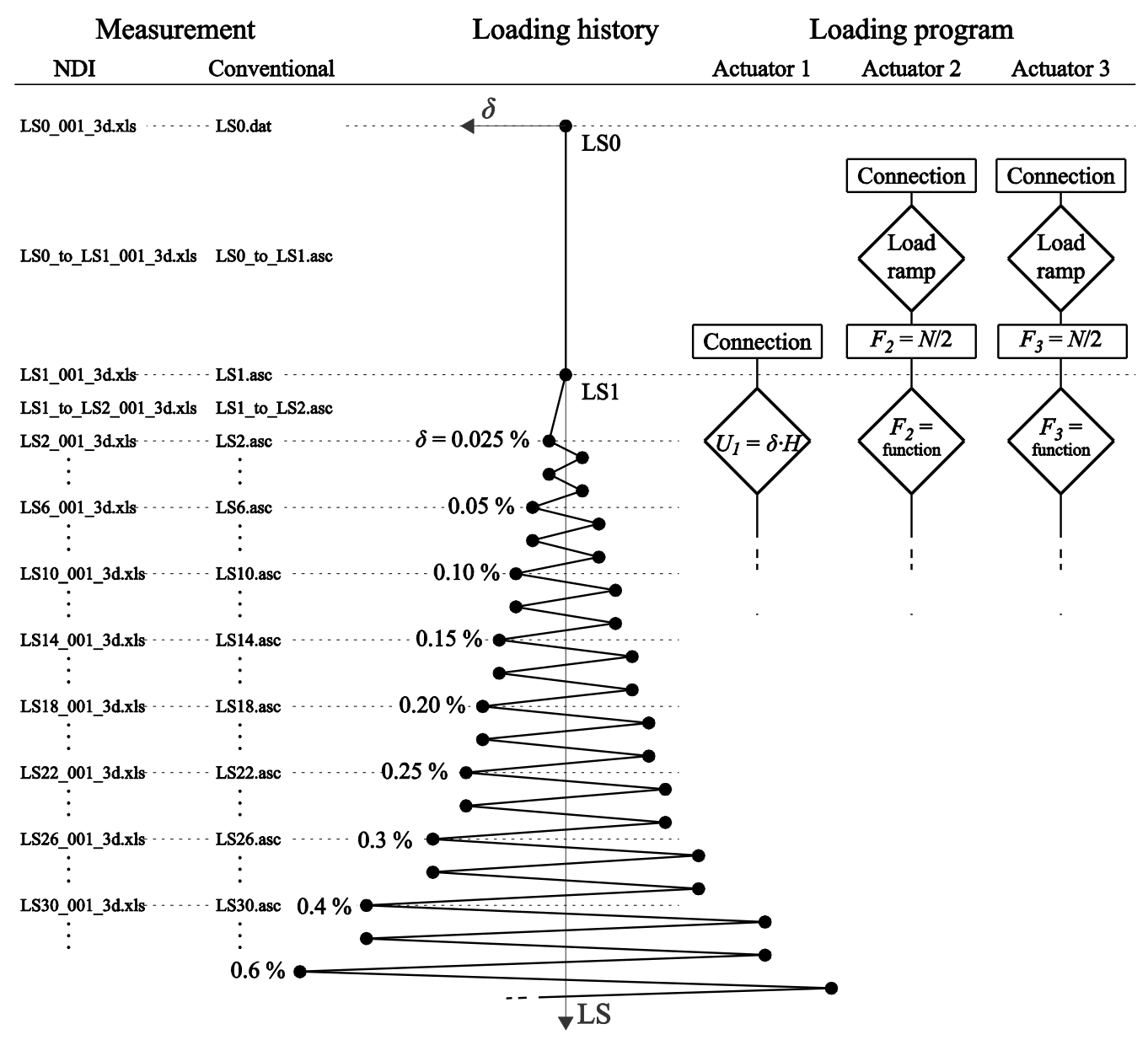

Figure 11. Testing procedure

TEST OBSERVATIONS AND SUMMARY OF RESULTS

\section{TEST OBSERVATIONS}

In the following we summarize the most important observations during testing. All cracks were marked on the walls and the crack tip annotated with the load step number. Photos were taken at all load steps and at zero load in between load steps and are provided along with the test data (for the organization of the data and photo see Section “Test Data").

The first wall, PUP1, was tested under double-fixed boundary conditions. Hence, the shear span was at approximately $0.5 H$. During the cycle with a nominal drift of $0.2 \%$, the horizontal actuator was not stopped in time and the wall was accidentally loaded up to a drift of $0.3 \%$. After a second full cycle of $0.2 \%$, the wall collapsed before reaching again a drift of $0.3 \%$. The crack pattern developed as follows: the first horizontal cracks in the joints at the top and the bottom of the wall appeared already during the cycles of $0.025 \%$ and $0.05 \%$ peak drift. The first diagonal cracks formed during the cycles of $0.1 \%$ peak 
drift and developed for both directions in form of two or three parallel stair stepped cracks through the mortar joints. At this stage, all cracks closed again when the loading was reversed. At the onset of strength degradation, i.e., after the peak strength was reached, the deformations started to concentrate in one diagonal crack, which did no longer close when the loading was reversed. This phenomenon developed in both loading directions and it was observed that axial load failure was provoked through the continuous deterioration of the zone where the diagonal cracks intersected (see Figure 12.a).

The second wall, PUP2, was tested with a shear span of $0.75 H$. The cracks developed in a similar fashion as in the first wall. The first cracks to appear were horizontal cracks in the joints of both bottom corners. Unlike for PUP1, however, the top part of the wall remained uncracked during the small amplitude cycles as the top moment was smaller than the bottom moment. With increasing drifts, the horizontal cracks grew in length and width and spread over an increasing height of the wall. At a drift of $0.1 \%$, the first diagonal cracks appeared as two or three parallel stair stepped cracks. When the lateral resistance dropped, the deformations for each loading direction, as for PUP1, concentrated in one diagonal crack and the axial load failure was caused by a continuous deterioration of the zone where the two diagonal cracks intersected (see Figure 12.b). When compared to PUP1, the first stair stepped cracks which appeared in PUP2 were steeper $(3: 2 \approx$ ver:hor) and turned with further displacement demand into a diagonal crack. Finally, the deformations started concentrating along one diagonal crack and a quite similar crack pattern was obtained at axial load failure for PUP2 and PUP1 (compare Figures 12.a and 12.b).

The third wall, PUP3, was tested with a shear span of 1.5H. PUP3 showed up to a drift of $\pm 0.4 \%$ a behavior dominated by flexural deformations. The deformations concentrated in the bed joints and the cracks extended over almost the entire height of the wall. First stair stepped cracks appeared only at drifts of $\pm 0.4 \%$. The bottom corner started crushing, before the deformations could concentrate in one diagonal crack, as it was observed for PUP1 and PUP2. The drop of lateral resistance was caused by the deterioration of these corners. Finally, axial load failure was provoked by the crushing of the central bricks at about one quarter of the height of the wall (see Figure 12.c).

For the fourth wall, PUP4, the normal force was increased by around $50 \%$ to $-619 \mathrm{kN}$. The shear span was kept constant at approximately 1.5H. PUP4 showed first a typical flexural behavior and, as for PUP3, the deformations concentrated mainly in horizontal cracks, which spread over almost the entire height of the wall. Diagonal cracks appeared 
first at the bottom of the wall at a nominal drift of $0.15 \%$. At a nominal drift of $0.25 \%$, vertical splitting cracks appeared at both bottom corners leading to the successive failure of the brick from the outer edge inwards. Axial load failure seemed to be caused by the continuous deterioration of the areas where vertical splitting cracks and diagonal cracks from both directions intersected (see Figure 12.d).

For the fifth wall, PUP5, the normal force was decreased by around $50 \%$ of the load applied to PUP1-3 to $-219 \mathrm{kN}$ and the shear span was $0.75 H$. At the end of the cycle with drift amplitude $0.6 \%$ (at LS37) the hydraulic system accidentally lost its pressure, which caused a sudden release of force in all three actuators (see last loop in Figure 13.f). After reloading in the positive direction (towards LS38 with a nominal drift of $+0.8 \%$ ), a significant residual drift remained. However, a significant drop in lateral force resistance was observed before (at LS37). The crack pattern developed as follows: the first horizontal cracks appeared during the cycles of $0.05 \%$ nominal drift in the base joint of the wall. The first stair stepped cracks formed during the cycles of $0.15 \%$ nominal drift. With further loading, more and more diagonal stair stepped cracks appeared, while the flexural deformations remained concentrated in horizontal cracks in the lower half of the wall. For both loading directions the lateral force dropped by more than $20 \%$ during the cycles of $0.6 \%$; this was also the cycle when deformations started to concentrate in one diagonal crack (see Figure 12.e).

The sixth wall, PUP6, was subjected to an asymmetric loading since the normal force and shear span were linearly dependent of the applied horizontal force during testing (see Equations (1) and (2)). In the negative direction, the boundary conditions approached those of PUP4 and in the positive direction those of PUP5. In both directions, first stair stepped cracks appeared during the cycles of $0.1 \%$ drift. In the positive direction, further parallel stair stepped cracks appeared during the cycles of $0.15-0.25 \%$ peak drift. In the negative direction, the behavior was dominated by vertical splitting cracks at the compressed corner which started to form during cycles with $0.2 \%$ nominal drift. While loading from a nominal drift of $+0.25 \%$ (LS24) to $-0.25 \%$ (LS25), the loading was accidentally started in the wrong direction. When this was noted, the applied drift was already $+0.35 \%$ and loading was stopped immediately and reversed towards $-0.25 \%$ (LS25). During the cycles with a nominal drift of $0.8 \%$, the deformations started concentrating along one diagonal crack when loading in the positive direction, while in the negative direction vertical splitting cracks developed now over the entire height of the wall (see Figure 12.f). A significant horizontal failure was attained while loading towards LS42 (nominal drift of 1.0\%) thus, it was decided to change loading direction before the 
axial load failure could occur in the same direction. Accordingly, horizontal and axial load failure occurred for the negative loading direction during cycles with $\pm 0.8 \%$. Note that these limit state drifts are approximately twice as large as those of PUP4.

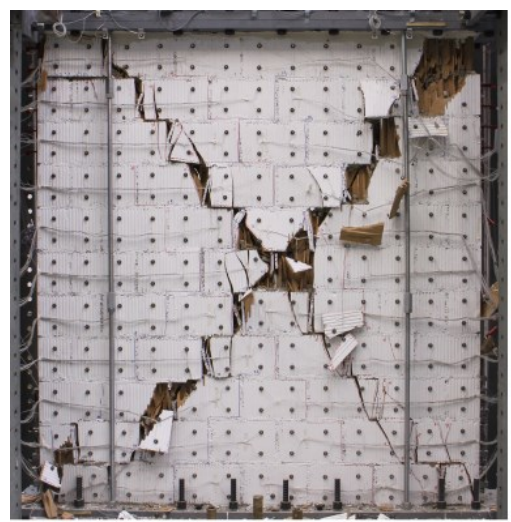

a) PUP1: $H 0 / H=0.5, N=-419 \mathrm{kN}$

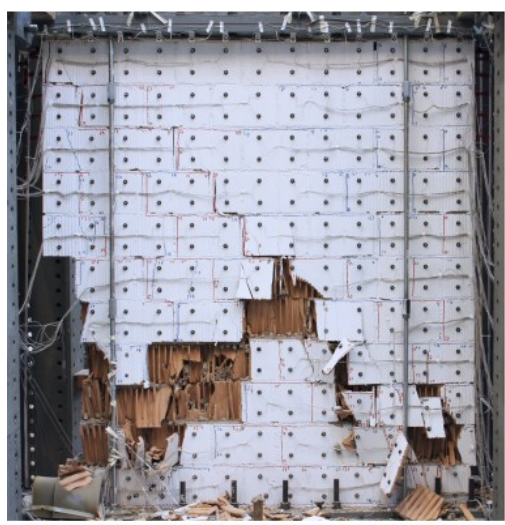

d) PUP4: $H 0 / H=1.5, N=-619 \mathrm{kN}$

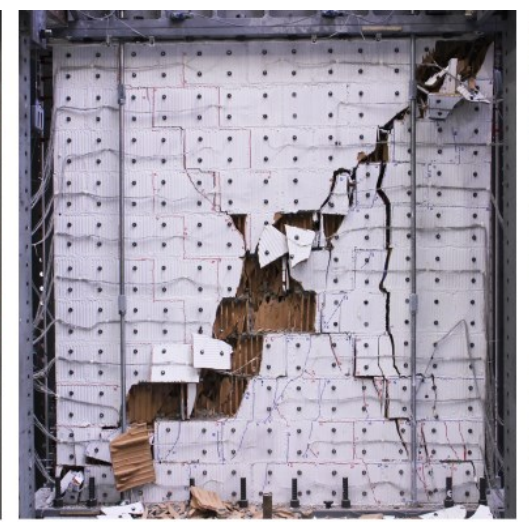

b) PUP2: $H 0 / H=0.75, N=-419 \mathrm{kN}$

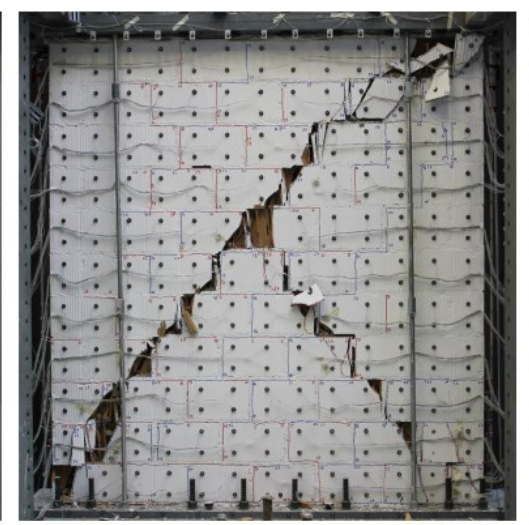

e) PUP5: $H 0 / H=0.75, N=-219 \mathrm{kN}$

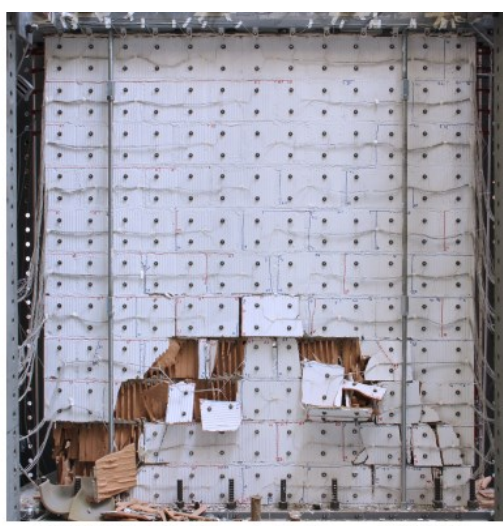

c) PUP3: $H 0 / H=1.5, N=-419 \mathrm{kN}$

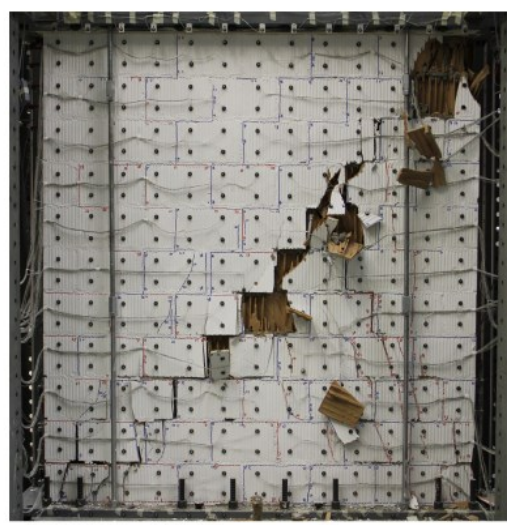

f) PUP6: $H 0 / H=v a r, N=v a r$.

Figure 12. Picture of all six walls when they could no longer sustain the applied axial load

\section{SUMMARY OF RESULTS}

The force-displacement hysteresis obtained from the optical and conventional measurement devices are shown in Figure 13. For the optical measurements, the horizontal displacements of LEDs glued onto the top steel plate were averaged (see row 24 in Figure 10), while the conventional displacement was measured at mid-height of the top beam (see position HOR2/3 in Figure 8). Hence, small differences can be noticed for large rotations of the top beam (e.g. PUP4). Figure 14 shows the moments at the top and bottom against the top rotation of the walls. Apart from PUP6 (see Section "Test program and test setup"), the ratio of top to bottom moment remained constant throughout one test.

Failure modes, peak load and drift at peak load, horizontal failure and maximum drift are summarized in Table 6. A comparison with a database of 64 tests can be found in Petry and Beyer (2014). 

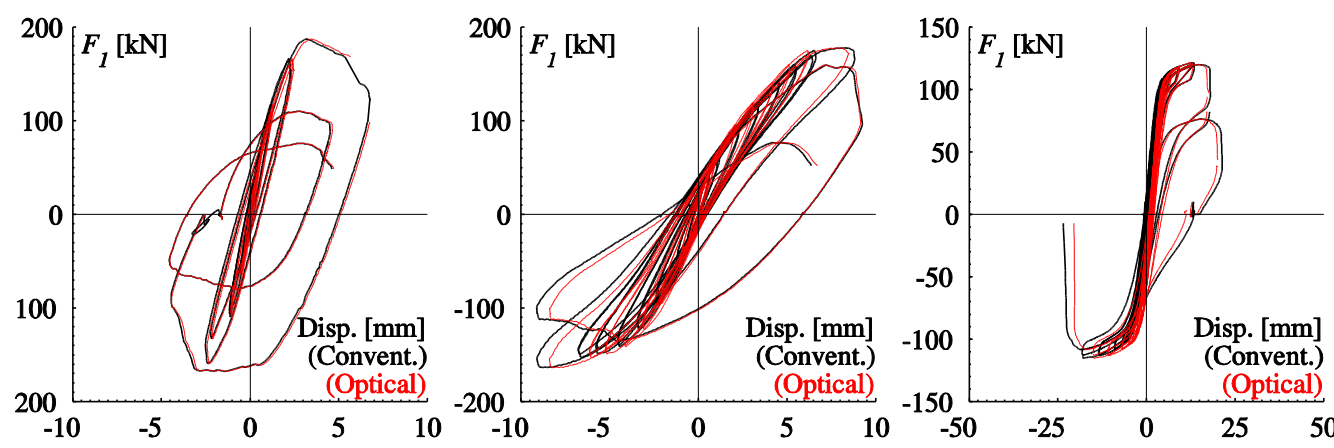

a) PUP1: $\sigma_{0} / f_{u}=0.18 ; H_{0}=0.5 H$

b) PUP2: $\sigma_{0} / f_{u}=0.18 ; H_{0}=0.75 H$
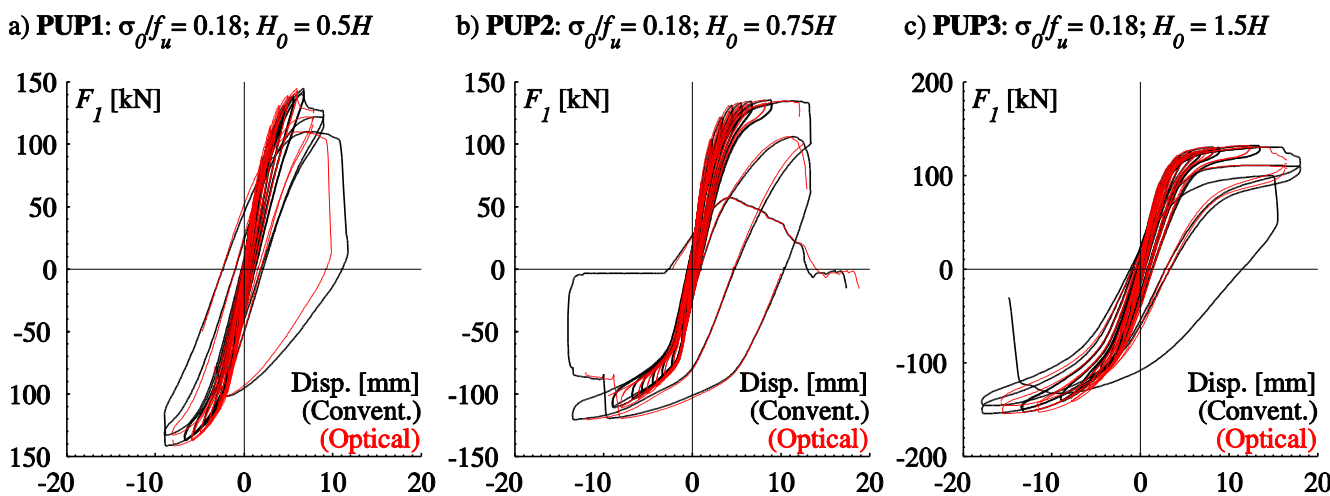

d) PUP4: $\sigma_{0} / f_{u}=0.26 ; H_{0}=1.5 H$

e) PUP5: $\sigma_{0} / f_{u}=0.09 ; H_{0}=0.75 H$

f) PUP6: $\sigma_{0} / f_{u}=$ var.; $H_{0}=$ var.

Figure 13. Displacement-force hysteresis; $\mathrm{x}$-axes: $\mathrm{CH} 2$ and $y$-axes: $\mathrm{CH} 45$ in black and $\mathrm{CH} 55$ in red with LS1 as reference
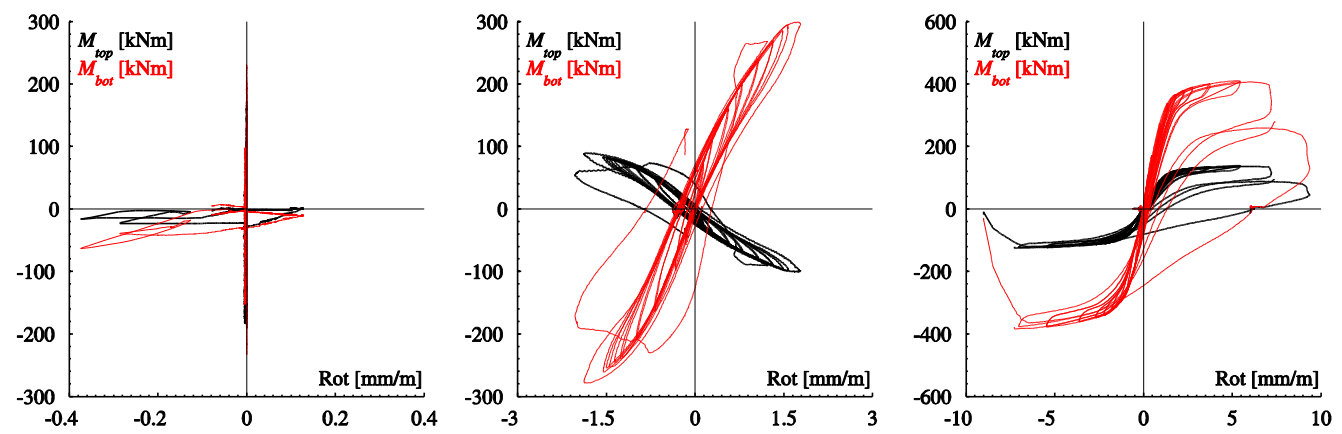

a) PUP1: $\sigma_{0} / f_{u}=0.18 ; H_{0}=0.5 H$

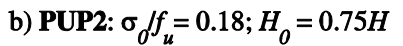

c) PUP3: $\sigma_{0} / f_{u}=0.18 ; H_{0}=1.5 \mathrm{H}$
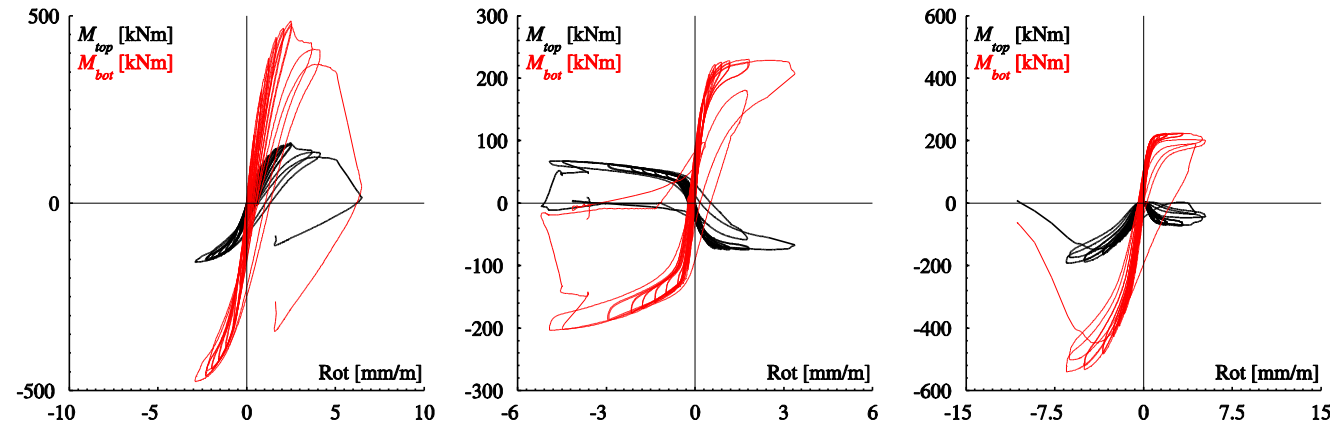

d) PUP4: $\sigma_{0} / f_{u}=0.26 ; H_{0}=1.5 H$

e) PUP5: $\sigma_{0} / f_{u}=0.09 ; H_{0}=0.75 H$

f) PUP6: $\sigma_{0} l f=$ var.; $H_{0}=$ var.

Figure 14. Top rotation-top moment hysteresis; $\mathrm{x}$-axes: $\mathrm{CH} 50$ and $y$-axes $\mathrm{CH} 47$ in black and CH48 in red with LS1 as reference 
Table 6. Summary of test results (Petry and Beyer 2014)

\begin{tabular}{|c|c|c|c|c|c|c|c|}
\hline Specimen & $\begin{array}{c}\text { Failure } \\
\text { mechanism }\end{array}$ & $\sigma_{0} / f_{u}$ & $H_{0} / H$ & Peak load & $\begin{array}{c}\text { Drift at } \\
\text { peak load }\end{array}$ & $\begin{array}{l}\text { Drift at hor. } \\
\text { failure }\end{array}$ & $\begin{array}{l}\text { Max. } \\
\text { drift }\end{array}$ \\
\hline PUP1 & Diagonal shear & 0.18 & $0.5 H$ & $187 \mathrm{kN}$ & $0.15 \%$ & $0.29 \%$ & $0.31 \%$ \\
\hline PUP2 & Diagonal shear & 0.18 & $0.75 H$ & $\begin{array}{r}178 \mathrm{kN} \\
-164 \mathrm{kN}\end{array}$ & $\begin{array}{r}0.35 \% \\
-0.37 \%\end{array}$ & $\begin{array}{r}0.40 \% \\
-\end{array}$ & $\begin{array}{r}0.41 \% \\
-0.38 \%\end{array}$ \\
\hline PUP3 & $\begin{array}{l}\text { Flexural } \\
\text { rocking }\end{array}$ & 0.18 & $1.5 H$ & $\begin{array}{r}121 \mathrm{kN} \\
-115 \mathrm{kN}\end{array}$ & $\begin{array}{r}0.51 \% \\
-0.72 \%\end{array}$ & $\begin{array}{r}0.72 \% \\
-0.93 \%\end{array}$ & $\begin{array}{r}0.84 \% \\
-0.94 \%\end{array}$ \\
\hline PUP4 & Hybrid failure & 0.26 & $1.5 \mathrm{H}$ & $\begin{array}{r}145 \mathrm{kN} \\
-142 \mathrm{kN}\end{array}$ & $\begin{array}{r}0.27 \% \\
-0.36 \%\end{array}$ & $\begin{array}{r}0.35 \% \\
-\end{array}$ & $\begin{array}{r}0.44 \% \\
-0.38 \%\end{array}$ \\
\hline PUP5 & Diagonal shear & 0.09 & $0.75 H$ & $\begin{array}{r}135 \mathrm{kN} \\
-121 \mathrm{kN}\end{array}$ & $\begin{array}{r}0.37 \% \\
-0.53 \%\end{array}$ & $\begin{array}{r}0.56 \% \\
-0.54 \%\end{array}$ & $\begin{array}{r}0.58 \% \\
-0.55 \%\end{array}$ \\
\hline PUP6 & Hybrid failure & $\begin{array}{l}0.26 \\
0.09\end{array}$ & $\begin{array}{r}1.5 \mathrm{H} \\
0.75 \mathrm{H}\end{array}$ & $\begin{array}{r}132 \mathrm{kN} \\
-154 \mathrm{kN}\end{array}$ & $\begin{array}{r}0.54 \% \\
-0.70 \%\end{array}$ & - & $\begin{array}{r}0.74 \% \\
-0.71 \%\end{array}$ \\
\hline
\end{tabular}

\section{TEST DATA}

\section{ORGANISATION OF THE DATA}

The data can be downloaded as one zip file from www.zenodo.org using the DOI $\underline{10.5281 / \text { zenodo.8443 }}$ (10 files of $0.98-1.3$ GB). The platform ZENODO (www.zenodo.org) was developed under the European FP7 project (http://www.openaire.eu/) and is hosted by the research facility CERN which operates a Large Hadron Collider.

Upon unzipping, the folder structure unfolds as follows (Figure 15): The data is organized first by specimen (PUP1-6 for the six walls, QUP for the diagonal compression tests, TUP for the triplet tests and WUP for the compression tests). For each wall specimen there are three subfolders ("photos", "unprocessed_data" and "processed_data") and for each type of material tests two subfolders ("unprocessed_data" and "processed_data"). The following sections outline the organization of the data within the individual folders and the processing applied to the data. Each wall folder contains one file "Metadata_conventional_channels.xls" which contains information on all instruments used (type of instrument, producer, measurement range, measurement unit, base length for displacement measurements, sign convention). 


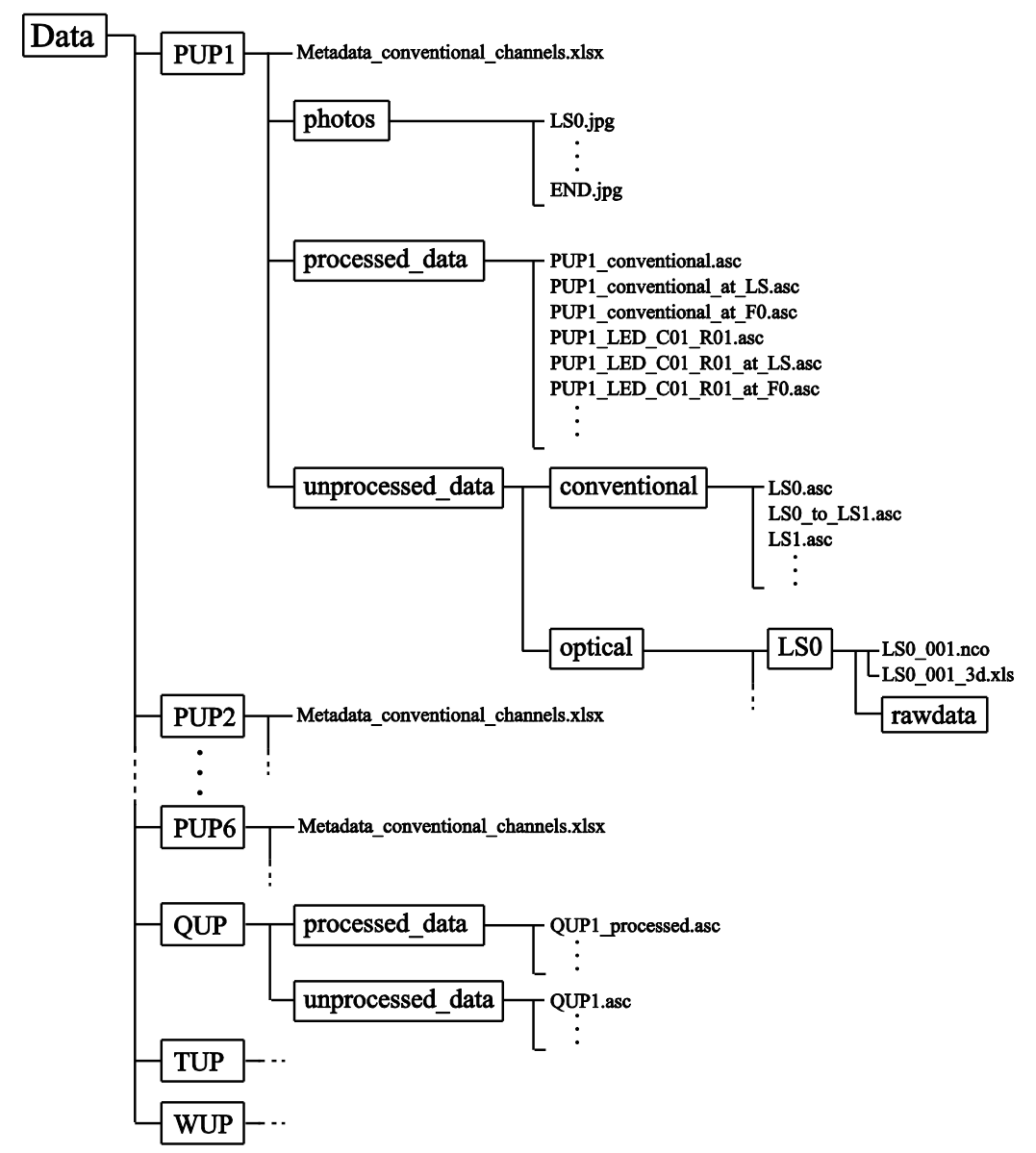

Figure 15. Organization of the data

\section{PHOTOS}

In addition to the data from conventional and optical measurements, photos are used to document the damage to the walls. Photos were taken at each load step, i.e. at peak displacements. These photos are labeled with "LSxx.JPG" where xx stands for the load step (see Figure 11 for the numbering of the load steps). To document the residual damage at zero horizontal force when passing from one load step to the other, the loading was shortly stopped for PUP2-6 when reaching $F_{1} \approx 0 \mathrm{kN}$. The photo at $F_{1} \approx 0 \mathrm{kN}$ between load steps $\mathrm{xx}$ and $\mathrm{xx}+1$ is labeled "LSxx_to_LSxx+1.JPG".

During testing, the cracks were traced using blue and red pens in order to render the cracks visible on photos. Cracks that were noticed for the first time at load steps in the positive loading direction (LS2, LS4, ...) were marked with a blue line and cracks that were noticed for the first time at load steps in the negative direction (LS3, LS5, ...) were marked in red. Cracks that appeared in the base joint during transportation or while fixing the bottom steel plate to the concrete foundation are marked and are annotated with 0 . Such cracks appeared for PUP3-6 but they remained limited to hairline cracks extending only over a small part of the wall length. 


\section{UNPROCESSED DATA}

The unprocessed data contains the original files recorded during the testing of the walls. The folder "unprocessed_data" contains two subfolders "conventional" and "optical".

\section{Conventional measurement data}

The conventional measurements were recorded using the system "CATMAN" (HBM 2000) and the files contain the unmodified output files of this system. They comprise the actuator forces $\left(F_{1}, F_{2}\right.$ and $\left.F_{3}\right)$, the voltage channel "NDI-channel" (see Section "Instrumentation"), the measurement from the internal displacement transducer of actuator $1\left(U_{1}\right)$, the measurements from the external displacement transducers $\left(U_{2}, U_{3}\right.$, HOR2, HOR3, $V_{2}$ and $V_{3}$ ) and the local displacement measurements at the corners of the wall (NB11 to ST33), see Figure 8. The voltage channel "NDI-channel" was exported from the NDI system and indicated when the optical measurement system was recording. The conventional measurement system was always started before and stopped after the optical measurement system and this voltage signal was therefore used to synchronize the two measurement systems. The folder "conventional" stores the following types of files, which are all ascii-files: The files containing the measurement during loading are labeled "LSxx_to_LSxx+1.asc". While holding the position at one load step, the data was written to a file labeled "LSxx.asc". When loading was interrupted during the night, the files labeled "LSxx_to_unload.asc" and "Restart_to_LSxx+1.asc" contain the corresponding half loadstep with the unloading/reloading part.

\section{Optical measurement data}

The folder "optical" contains the output of the NDI measurement system. For each recording sequence a separate folder was created which stores the NDI-specific file formats (raw data and sensor settings) and the measurement data exported to Excel. The folders are named "LSxx_to_LSxx+1" for measurements when loading from one load step to the next and "LSxx" for measurements at one load step. For the latter, the data was recorded for 90 to 120 seconds. The Excel-files carry the same names as the folders plus the suffix “_001_3d.xls": “LSxx_to_LSxx+1_001_3d.xls" and "LSxx_001_3d_xls".

Each Excel-file contains three header lines which indicate the number of frames included in this file, the recording frequency in $\mathrm{Hz}$ (2 $\mathrm{Hz}$ for PUP1 and $4 \mathrm{~Hz}$ for PUP2-6) and the units of the coordinate measurements (mm). After one blank line, the actual measurement data is organized in columns. The first column stores an index starting always from 1 . The second and following columns give the coordinate measurements of 
the LEDs. Always three columns store the $\mathrm{x}-, \mathrm{y}-$, and $\mathrm{z}$-coordinate measurements of one LED. The labels of these columns are for LED number 1 Marker_1x, Marker_1y, Marker_1z. Note that the LED numbers are at this stage random and the numbering indicated in Figure 10 only applies to the processed data. If the LED-coordinates could not be measured because the LED was not visible for the position sensor, the columns corresponding to this LED do not contain any entries.

\section{Irregularities with regard to the measurements}

When the horizontal actuator was not stopped in time for PUP1 (during the cycle with a nominal drift of $0.2 \%$, LS13 to LS14) and the wall was accidentally loaded up to a drift of $0.3 \%$, the optical and conventional measurement systems were not recording during this phase. For PUP3, no measurements are available for LS9_to_LS10, LS39_to_LS40 and parts of the optical measurement for LS20_to_LS21 and LS34_to_LS35 are missing. While testing PUP5, the NDI measurement for LS36_to_LS37 was started only after unloading and reaching $F_{1} \approx 0 \mathrm{kN}$.

\section{PROCESSED DATA}

The processing of the data served four objectives: (1) synchronization of the optical data with the conventional measurement data; (2) reducing the data to make it more manageable; (3) to reorganize the data in two data sets - one for measurements at load steps and one for measurements containing the actual loading process between load steps; (4) to remove any bias or data that is not linked to the actual behavior of the test unit.

For each test, the data acquired during loading is appended to one continuous vector of 10000-15000 data points. The data recorded at a load step was averaged and hence, condensed to one single measurement point. A second file contains these measurement points for all load steps (19 to 50 data points, depending on the number of loadsteps until failure). In addition, the data recorded at $F_{1} \approx 0 \mathrm{kN}$ between two successive load steps was identified and also condensed to one point. This data describes the residual deformations for zero horizontal force and is contained in a third file. The suffix of each file ("_at_LS", “_at_F0" or none for the loading phase from peak to peak) indicates the type of file (see Figure 15).

\section{Processing of the conventional measurement data}

With the exception of the channels containing the forces $F_{1}, F_{2}$ and $F_{3}$, the signal coming from the NDI measurement and the time, all channels were shifted to zero in such a way that the displacement at LS0 corresponds to zero. The sign of the force of actuator 
$1, F_{1}$, the displacement measurements $V_{2}$ and $V_{3}$ and the deformation measurements NB11 to ST33 were inverted in order to match the sign convention described in "Metadata_conventional_channels.xls" (see also Figure 1). Furthermore, the conventional data was carefully processed to remove any bias or data that is not linked to the actual behavior of the test data (e.g. offsets because conventional instruments were moved during testing). This process involved certain judgment; in case of doubt the data was not modified.

The self-weight of the loading beam $(\sim 19 \mathrm{kN})$ was added to the axial load applied at the top of the walls; the weight of the horizontal actuator was neglected since it was supported by straps (Figure 1.b). Thus, the force applied by the two vertical actuators 2 and 3 was adjusted as follows:

$$
F_{2,3}=F_{2,3}-\frac{19 \mathrm{kN}}{2}
$$

In addition to the recorded channels, a set of computed channels was added to the processed data. The objective of these computed channels is to allow the user to quickly plot fundamental graphs such as the shear force-average drift hysteresis of the wall. Table 7 defines these computed channels: CH53 was obtained by averaging the displacement from all LEDs glued onto the top steel plate. CH54 contains entries only when the optical measurements were missing, hence, when $\mathrm{CH} 53$ indicates a $\mathrm{NaN}$-value $(\mathrm{NaN}=\mathrm{Not}$ a Number). In this case, $\mathrm{CH} 44$ is taken as replacement and shifted in such a way as to remove any offsets between $\mathrm{CH} 53$ and $\mathrm{CH} 54$. The final displacement of the top plate of the wall is channel $\mathrm{CH} 55$, which assembles channels $\mathrm{CH} 53$ and $\mathrm{CH} 54$. CH56 stores the average drift which was obtained by dividing the displacement of the top plate (CH55) by the average height of the wall as obtained from LS0 measurements. 
Table 7. Computed channels

\begin{tabular}{|c|c|c|c|c|c|}
\hline $\begin{array}{l}\text { Channel } \\
\text { number }\end{array}$ & $\begin{array}{l}\text { Channel } \\
\text { name }\end{array}$ & Unit & Shortcut & Formulae/Explanation & Sign convention \\
\hline 44 & $\begin{array}{l}\text { Average } \\
\text { HOR }\end{array}$ & $\mathrm{mm}$ & - & $\frac{(\mathrm{HOR} 2+\mathrm{HOR} 3)}{2}$ & $\begin{array}{l}+=\text { towards South } \\
-=\text { towards North }\end{array}$ \\
\hline 46 & $\begin{array}{l}\text { Normal } \\
\text { force }\end{array}$ & $\mathrm{kN}$ & $N$ & $F_{2}+F_{3}$ & $\begin{array}{l}+=\text { pulling to top } \\
-=\text { pushing to bottom }\end{array}$ \\
\hline 47 & $\begin{array}{l}\text { Top } \\
\text { moment }\end{array}$ & $\mathrm{kNm}$ & $M_{\text {top }}$ & $\left(F_{2}-F_{3}\right) \cdot \frac{L_{a c t}}{2}+F_{1} \cdot H_{a c t}$ & See Figure 1.a \\
\hline 48 & $\begin{array}{l}\text { Bottom } \\
\text { moment }\end{array}$ & $\mathrm{kNm}$ & $M_{\text {bot }}$ & $\left(F_{2}-F_{3}\right) \cdot \frac{L_{a c t}}{2}+F_{1} \cdot\left(H+H_{a c t}\right)$ & See Figure 1.a \\
\hline 49 & $\begin{array}{l}\text { Shear } \\
\text { span }\end{array}$ & $\mathrm{m}$ & $H_{0}$ & $\frac{M_{b o t}}{M_{b o t}-M_{t o p}} \cdot H$ & - \\
\hline 50 & $\begin{array}{l}\text { Rotation } \\
\text { from U2 } \\
\text { and U3 }\end{array}$ & $\mathrm{mm} / \mathrm{m}$ & - & $\frac{U_{2}-U_{3}}{d_{U 2}+d_{U 3}+L}$ & $\begin{array}{l}+=\text { counter clockwise } \\
-=\text { clockwise }\end{array}$ \\
\hline 51 & $\begin{array}{l}\text { Rotation } \\
\text { from V2 } \\
\text { and V3 }\end{array}$ & $\mathrm{mm} / \mathrm{m}$ & - & $\frac{V_{2}-V_{3}}{d_{V 2}+d_{V 3}+L}$ & $\begin{array}{l}+=\text { counter clockwise } \\
-=\text { clockwise }\end{array}$ \\
\hline 53 & $\begin{array}{l}\text { Disp at } \\
\text { top plate }\end{array}$ & $\mathrm{mm}$ & - & $\begin{array}{l}\text { Average displacement obtained } \\
\text { from LEDs glued onto the top steel } \\
\text { plate }\end{array}$ & $\begin{array}{l}+=\text { towards South } \\
-=\text { towards North }\end{array}$ \\
\hline 54 & $\begin{array}{l}\text { Missing } \\
\text { disp }\end{array}$ & $\mathrm{mm}$ & - & $\begin{array}{l}\text { Displacement obtained from CH44, } \\
\text { where measurement from LEDs is } \\
\text { missing }\end{array}$ & $\begin{array}{l}+=\text { towards South } \\
-=\text { towards North }\end{array}$ \\
\hline 55 & $\begin{array}{l}\text { Disp at } \\
\text { top plate }\end{array}$ & $\mathrm{mm}$ & - & $\begin{array}{l}\text { Displacement obtained from CH53 } \\
\text { and CH54 }\end{array}$ & $\begin{array}{l}+=\text { towards South } \\
-=\text { towards North }\end{array}$ \\
\hline 56 & Drift & $\%$ & - & $\frac{\text { CH55 }}{\text { MarkersPosition }}$ & $\begin{array}{l}+=\text { towards South } \\
-=\text { towards North }\end{array}$ \\
\hline
\end{tabular}

\section{Processing of the optical measurement data}

To remove any inherent noise, the optical measurement data was smoothed over a range of 20 data points using the Matlab-function "smooth" (Matlab 2010). The coordinate system was then rotated and shifted to align the axes with the xy-axes as indicated in Figure 10. Finally, the data was synchronized with the processed conventional measurements. In order to have the same number of entries for the conventional and optical measurements, the measurement frequency of the optical measurements was reduced leading to $150-500$ data points between peak displacements. LEDs that fell off during testing were identified and the corresponding entries were replaced by $\mathrm{NaN}$-entries. NaN-entries were also assigned when LED-coordinates were not recorded. Finally, the LEDs were renumbered indicating the position of the LED by a row and a column number (Figure 10). The coordinate histories of each LED are stored in an ascii-file with three columns for the $\mathrm{x}-$, $\mathrm{y}-$, and $\mathrm{z}$-coordinate.

The files are named "LED_Rxx_Cyy.asc", where xx corresponds to the row number and yy to the column number (see Figure 10). For PUP1 and PUP2 only four LEDs were 
glued onto the top and bottom steel plate. These two times four LEDs are saved in the files LED_R01_Cyy and LED_R24_Cyy which corresponded to the nearest position of the LEDs. The remaining files were filled with $\mathrm{NaN}$-values in order to simplify the batch processing of the walls.

\section{DATA FOR MATERIAL TESTS (QUP, TUP AND WUP)}

Data from the material tests was processed similar to the conventional data from the wall tests. Hence, all channels were set to zero at zero load and any bias or data that is not linked to the actual behavior of the test data was eliminated (e.g. offsets because conventional instruments were moved during testing).

\section{EXAMPLES OF DERIVED DATA}

This section gives some examples of graphs and figures that can be produced using the experimental data; further examples can be found in Petry and Beyer (2014). All plots are created using the derived data.

\section{EXAMPLE PLOTS FOR GLOBAL BEHAVIOR}

Current codes (e.g. CEN 2004) suggest that the deformation capacity of masonry walls is directly linked to the failure mechanism of the wall. However, recent research showed that this approximation is insufficient and that the displacement capacity of URM walls depends on more than only the failure mechanism (Petry and Beyer 2014). The development of deformation mechanisms could up to now only be inferred from crack patterns. The optical measurements taken during this series allow drawing amplified deformed shapes of the walls. Figure 16 shows as example the amplified deformed shapes of PUP4 at different load steps; PUP4 was chosen because the behavior was initially dominated by flexural deformations while the test unit developed subsequently important diagonal shear cracks. Figure 16 shows the deformed shapes at LS18 and $19\left(\delta_{\text {nom }}=\right.$ $0.25 \%)$ and 30 and $31\left(\delta_{\text {nom }}=0.6 \%\right)$. The photos that were taken at the same load steps are shown in Figure 17. The amplified deformed shapes were computed as follows: The rigid body translation and rotation of each brick were computed from the average displacements of the four LEDs on the brick. From the same four LEDs, the average strain state of the brick was computed $\left(\varepsilon_{x}, \varepsilon_{y}, \gamma_{x y}\right)$. It was assumed that the entire brick was subjected to this strain state. The deformed shape of the brick and its rigid body movement were amplified by a factor AF and the deformed brick was plotted at its new position. All bricks together give the amplified deformed shape (Figure 16). Such plots 
allow identifying clearly the development of failure mechanisms and can be regarded as an important complement to photos of crack patterns (Figure 17).
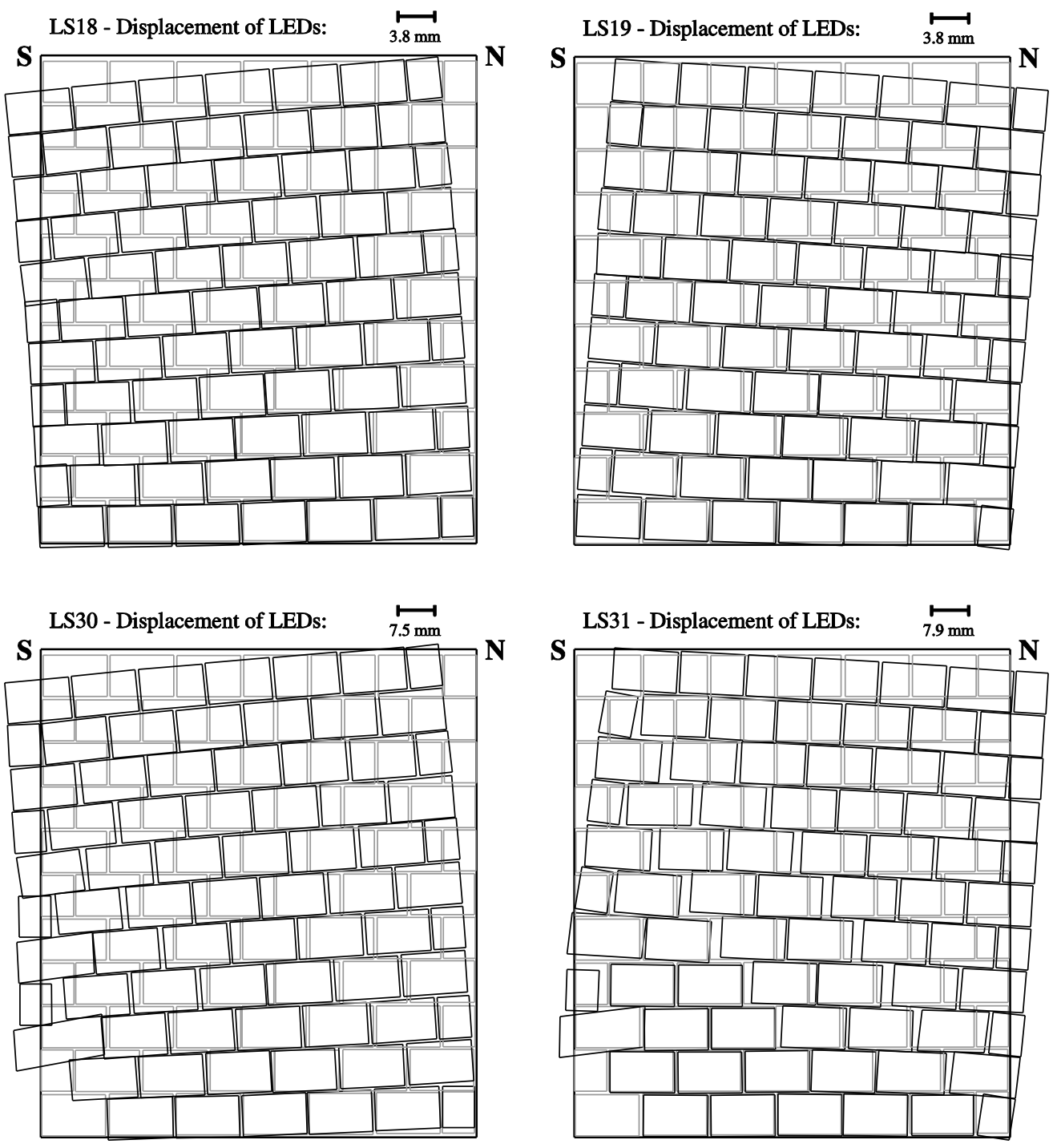

Figure 16. Amplified deformed shapes for LS18 and LS19 (AF $\approx 45)$ and LS30 and LS31 $(\mathrm{AF} \approx 22)$ (PUP4, reference load step: LS0). 


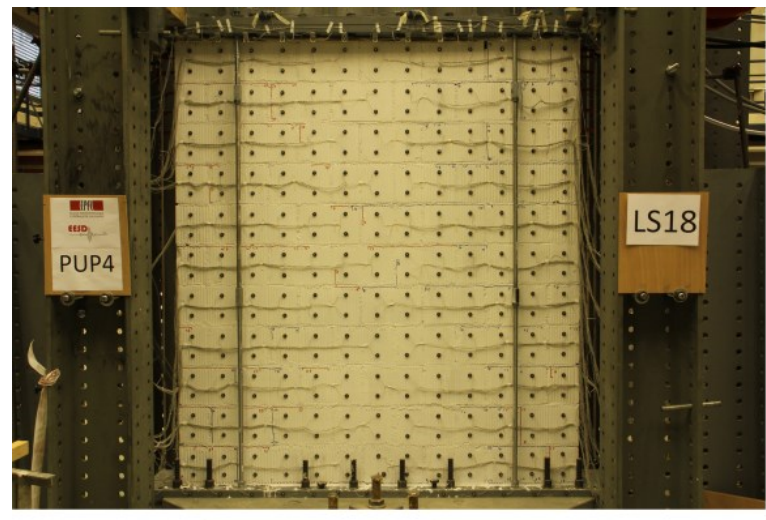

a) PUP4: $H 0 / H=1.5, N=-619 \mathrm{kN}, \mathrm{LS} 18$

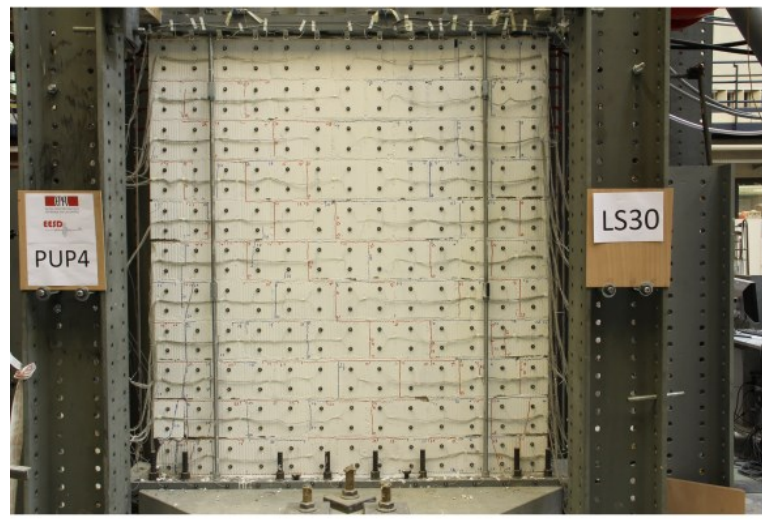

c) PUP4: $H 0 / H=1.5, N=-619 \mathrm{kN}, \mathrm{LS} 30$

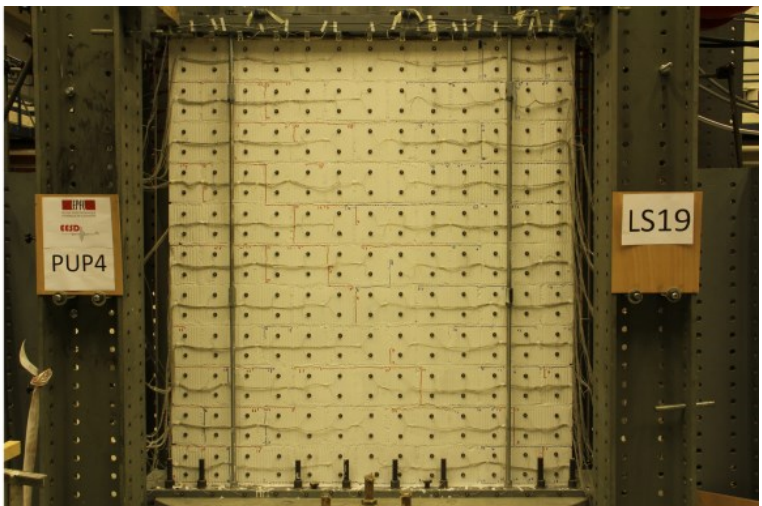

b) PUP4: $H 0 / H=1.5, N=-619 \mathrm{kN}, \mathrm{LS} 19$

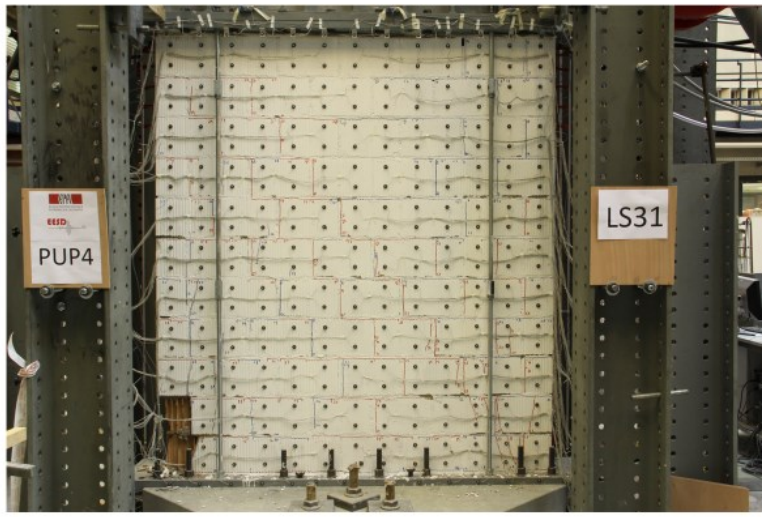

d) PUP4: $H 0 / H=1.5, N=-619 \mathrm{kN}, \mathrm{LS} 31$

Figure 17. Photos of PUP4 taken at the load steps LS18, LS19, LS30 and LS31

\section{EXAMPLE PLOTS FOR LOCAL BEHAVIOR}

The LED-data can also be used to compute local deformations such as average strains and crack widths. Figure 18 shows as example average strains at the compressed face of the wall. The strains were computed from the LEDs in column 1 and 13 for loading towards South (even load steps) and North (uneven load steps), respectively. The strains were computed as average strains between the center lines of bricks bridging therefore always one brick and one bed joint. The plots show clearly that the compressive strains concentrate in the bottom four brick rows. They also show that the bed joints 7 and 8 were particularly weak, most likely due to poor quality of the mortar used for the construction of these bed joints. Figure 19 shows the deformations in the bed joints which were computed using the same assumptions as for the deformed shapes (uniform strain state in bricks). 


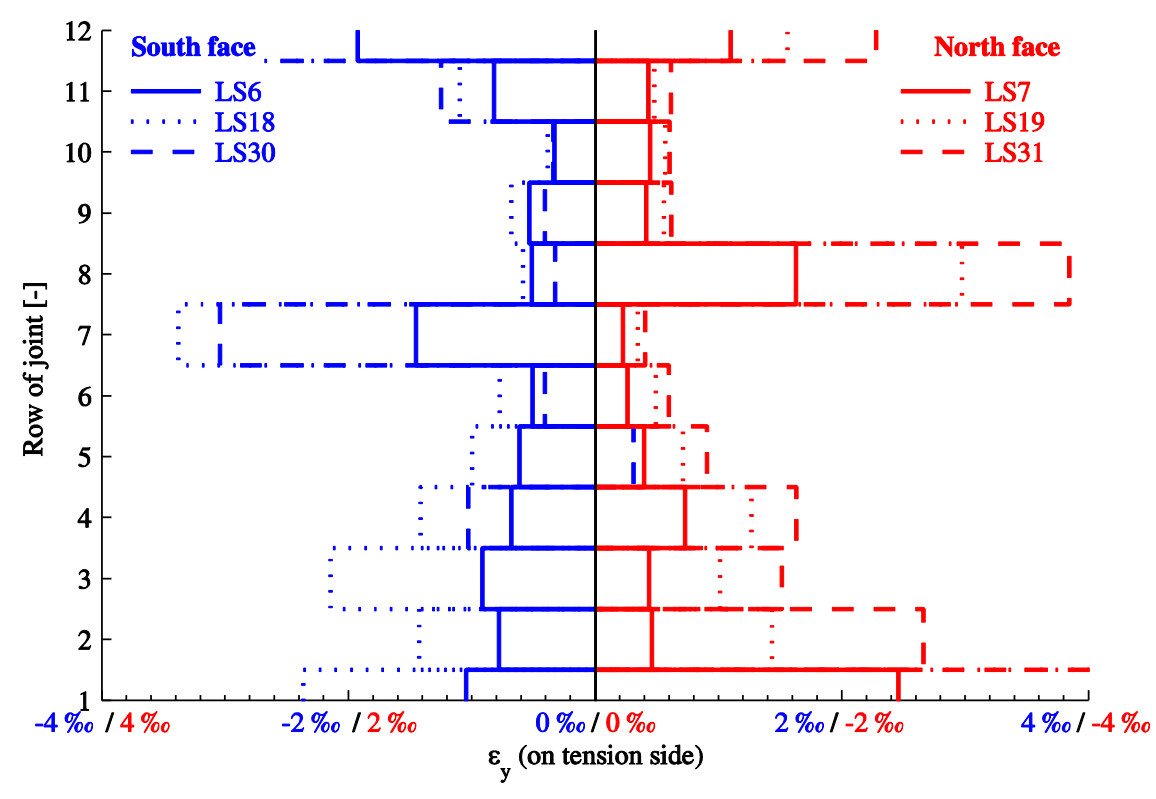

Figure 18. Strain at compressed edge of the wall (PUP4, reference load step LS0)
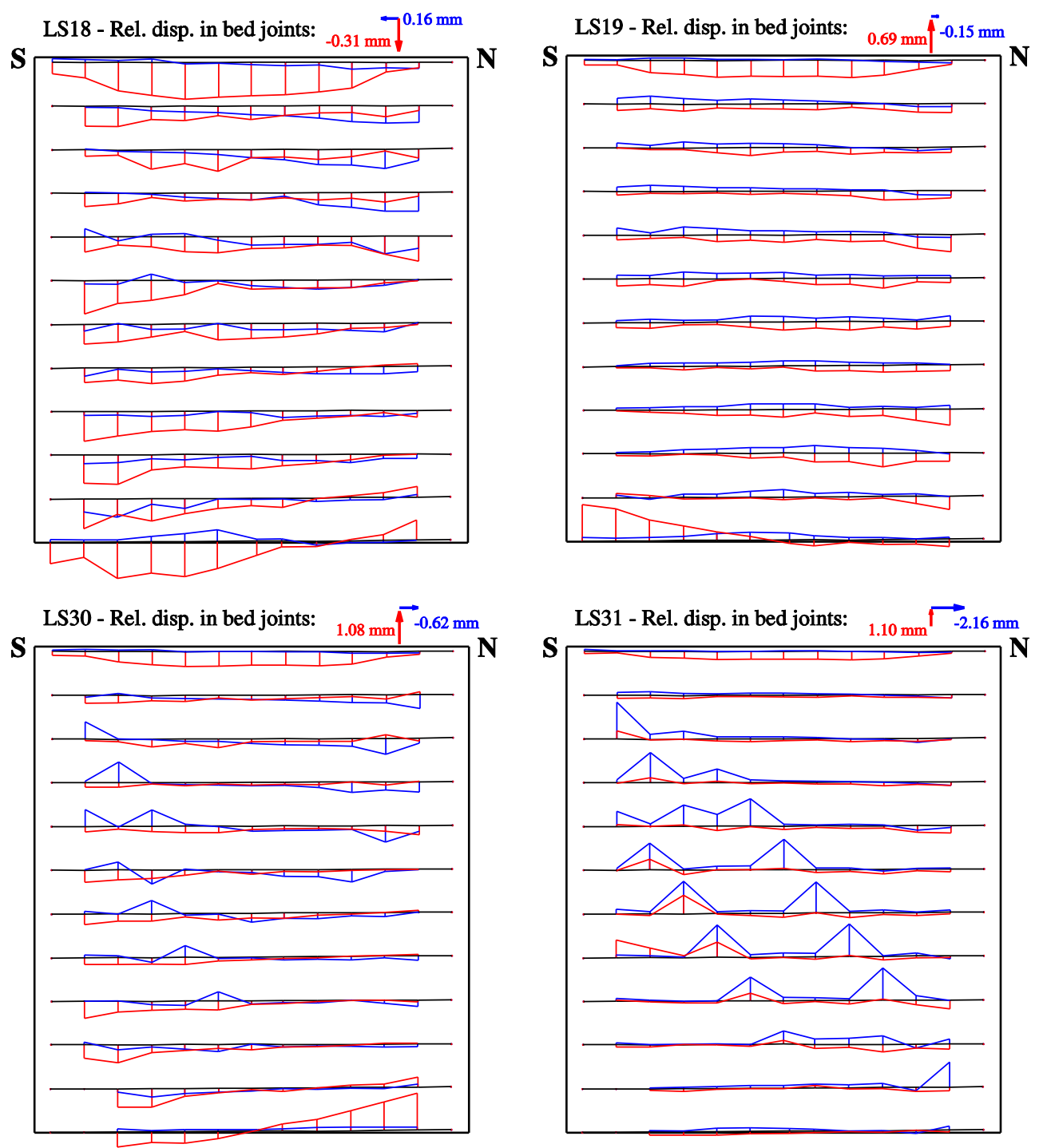

Figure 19. Horizontal slip (in blue) and vertical opening/compression (in red) of the bed joints for different load steps (PUP4, reference load step LS0) 


\section{SUMMARY}

The paper presents the data of six quasi-static cyclic tests on masonry walls, which is publically accessible through the ZENODO platform. The data is unique with regard to the boundary conditions applied to the walls and the detail of local deformation measurements recorded. Example plots show how these local deformation measurements can be used to analyze in depth the behavior of the masonry walls. Such data is crucial for advancing numerical and analytical models for the deformation capacity of masonry walls - the latter are an important step towards performance-based design and assessment procedures for unreinforced masonry structures.

\section{ACKNOWLEDGMENTS}

The authors thank Morandi Frères SA for the donation of the bricks and all engineers, technicians and students who helped with the laboratory testing. The authors would like to thank in particular Dr. Pia Hannewald, Sylvain Demierre, Gérald Rouge, Nikita Saugy and Nicholas Molyneaux.

\section{REFERENCES}

Beyer, K., and A. Dazio, 2012a. Quasi-Static Cyclic Tests on Masonry Spandrels. Earthquake Spectra 28 (3), 907-929.

Beyer, K. and A. Dazio, 2012b. Quasi-static monotonic and cyclic tests on composite spandrels, Earthquake Spectra 28 (3), 885-906.

Bosiljkov, V., Page, A. W., Bokan-Bosiljkov, V., and R. Zarnic, 2003. Performance based studies of in-plane loaded unreinforced masonry walls. Masonry International 16 (2), 39-50.

European Committee for Standardisation (CEN), 2002. EN 1052-1: Methods of test for masonry - Part 1: Determination of compressive strength. Design Code EN 1052-1:1998-12, Brussels, Belgium.

European Committee for Standardisation (CEN), 2004. Eurocode 8: Design of structures for earthquake resistance - Part 3: Assessment and retrofitting of buildings. Design Code EN 19983, Brussels, Belgium.

European Committee for Standardisation (CEN), 2007. EN 1052-3: Methods of test for masonry - Part 3: Determination of initial shear strength. Design Code EN 1052-3:2002-10, Brussels, Belgium.

Frumento, S., Magenes, G., Morandi, P., and G. M. Calvi, 2009. Interpretation of experimental shear tests on clay brick masonry walls and evaluation of q-factors for seismic design. Technical Report, IUSS PRESS, Pavia, Italy.

Gams, M., and M. Tomaževič, 2013. Influence of different types of units and mortars on seismic resistance of masonry walls. Proceedings of the $12^{\text {th }}$ Canadian Masonry Symposium, Vancouver, Canada.

Ganz, H. R., and B. Thürlimann, 1984. Versuche an Mauerwerksscheiben unter Normalkraft und Querkraft. Test Report 7502-4, ETH Zürich, Switzerland (in German).

Goodnight, J., Kowalsky, M., and J. Nau, 2013. Effect of Load History on Performance Limit States of Circular Bridge Columns. Journal of Bridge Engineering 18, SPECIAL SECTION: 
Eurocodes and Their Implications for Bridge Design: Background, Implementation, and Comparison to North American Practice, 1383-1396.

HBM, 2000. Catman Data acquisition Software, Hottinger Baldwin Messtechnik GmbH, Darmstadt, Deutschland, http://www.hbm.com/en/menu/products/software/data-acquisitionsoftware.

Lowes, L. N., Lehman, D. E., Birely, A. C., Kuchma, D. A., Marley, K. P., and C. R. Hart, 2012. Earthquake response of slender planar concrete walls with modern detailing. Engineering Structures 43, 31-47.

NDI, 2011. Optotrak Certus HD, Northern Digital Inc., Waterloo, Ontario, Canada, http://www.ndigital.com/industrial/certushd.php.

Magenes, G., Morandi, P., and A. Penna, 2008. Enhanced safety and efficient construction of masonry structures in europe - $d$ 7.1c test results on the behavior of masonry under static cyclic in plane lateral loads. Report ESECMaSE D 7.1c, University of Pavia, Pavia, Italy.

Matlab, 2010. Matlab Version 7.10.0.499 (R2010a), The Mathwork Inc., Natick, Massachusetts, United States, http://www.mathworks.ch.

Petry, S., and K. Beyer, 2014. Influence of boundary conditions and size effect on the drift capacity of URM walls. Engineering Structures 65, 76-88.

Priestley, M. J. N., Calvi, G. M., and M. J. Kowalsky, 2007. Direct Displacement Based Design. Book, IUSS PRESS, Pavia, Italy.

RILEM, 1991. RILEM TC 76-LUM: Diagonal tensile strength tests of small wall specimens. RILEM Publications SARL.

Salmanpour, A., Mojsilović, N., and J. Schwartz, 2013. Experimental study of the deformation capacity of structural masonry. Proceedings of the $12^{\text {th }}$ Canadian Masonry Symposium, Vancouver, Canada.

Vermeltfoort, A. Th., Raijmakers, Th. M. J., and H. J. M. Janssen, 1993. Shear tests on masonry walls. Proceedings of the Sixth North American Masonry Conference, Philadelphia, Pennsylvania, pp. 1183-1193.

Walter and Bai, 2011. 3 Servo-Hydraulic Differential Actuators Type DPZ 1000/1000 with 3Channel Hydraulic Svice Manifold and Command Unit Type AZ 150-3-280 and Software DION7, Walter+Bai AG Testing Machines, Löhnnigen, Switzerland, http://www.walterbai.com. 